\title{
COVID-19 Deaths Linked to Restrictions Stringency Lag: A G7 and Global Analysis, Implications for Public Policy
}

\author{
Marcella Lucchetta ${ }^{1}$, Lois Tullo ${ }^{2}$ \\ ${ }^{1}$ Department of Economics, University Ca' Foscari, Venice, Italy \\ ${ }^{2}$ Schulich School of Business, York University, Toronto, Canada; Executive in Residence, Global Risk Institute, Toronto, Canada \\ Email address: \\ lucchett@unive.it (M. Lucchetta), ltullo@yorku.ca (L. Tullo), ltullo@jlt.net (L. Tullo)
}

\section{To cite this article:}

Marcella Lucchetta, Lois Tullo. COVID-19 Deaths Linked to Restrictions Stringency Lag: A G7 and Global Analysis, Implications for Public Policy. International Journal of Economics, Finance and Management Sciences. Vol. 9, No. 4, 2021, pp. 134-158.

doi: 10.11648/j.ijefm.20210904.12

Received: June 29, 2021; Accepted: July 12, 2021; Published: August 2, 2021

\begin{abstract}
This study focuses on the results of the G7 countries from the analysis of daily data from 184 countries of the world during the COVID-19 epidemic. After an increase in restrictions, there is an increase in new COVID-19 deaths. To understand the influences on number of deaths by country, the analysis reveals that per capita income is significantly positively correlated with mortality from COVID-19. This suggests that the epidemic first hit rich countries the hardest through the correlation to the human development index. This finding was contrary to what was predicted by the Global Health Security Index on pre-pandemic preparedness. Within affluent countries, deaths and cases were higher among socio-economic challenged populations. This was supported by the number of deaths that are positively influenced by the GINI index that is an indicator of disparity of income and wealth. The research indicates that after an increase in restrictions, there is an increase in new COVID-19 deaths and cases. This along with the finding on the stringency index, correlated with the stringency lag, point to the effectiveness of policies being negatively correlated due to a lag in implementation and partial application. Moreover, the uncertainty or the variability of the stringency index has a negative impact on mortality. The "Power Distance" by was used to understand individual's reaction to restrictions indicated by the stringency index and the stringency lag, COVID-19 death numbers were also found to be positively influenced by a countries "Power Distance". These findings are key to the improve policy management of the virus. The Delta plus and Lambda variant's increased transmissibility and potential vaccine resistance increases the urgency for policy makers to understand and immediately enforce the stringency of regulations in consideration of their countries Power Balance index, and to reduce the stringency lag of their policies to increase the effectiveness in reducing the transmission of COVID-19.
\end{abstract}

Keywords: COVID-19, Variant, Nonfinancial Risk Management, Public Policy, Mathematics, Spread of Viral Disease, GRAFT, Finance

\section{Introduction}

The whole world is facing a growing number of complex and interconnected challenges. Recently, many risks of different nature are intertwining and strengthening with each other, generating a dangerous accumulation in some points of the world system. Epidemic risks are inevitably linked to economic, financial, political stability risks and many other possible risks committed as evidenced by the various reports of the World Economic Forum (WEF). The WEF 2020 report identified the potential severity of a pandemic, however, did not give much evidence to the likelihood risk of pandemics. The WEF 2021 increased the spread of viral disease to the most severe and $2^{\text {nd }}$ most likely, with the greatest inter-relationships with increasing Social Cohesion Erosion, and Debt Crisis.

Social and financial-economic systems are embedded in a complicated (complex) and connected world. Helbing D. [9] links the five global risks though networks, Tullo [19] links the correlations of five global clusters through the Global Risk and Trends Framework (GRAFT) and Tullo [20] focuses on the interrelationship of theses risk clusters and COVID-19.

In short, we can say with certainty that no phenomenon can, now more than ever, be studied alone, or without taking into account the consequences on all other variables. 
Political, economic, and social tensions are growing. In the areas affected by the COVID-19 pandemic, fear, crime and uncertainty increases, and the economic-financial system collapses: which is only the latest result. At the root there are fears and risks, especially this one, as serious as survival, living with a contagious disease, or lingering LongCovid.

Importantly, Szymanski et al [18] documents the failure of global risk networks approach: without identification the network is unable to precisely estimate the risks. An example of this failure was the underestimation of the pandemic risk that some philosophers had already thought of, highlighting the great potential of biological research in the hands of nations with few safety protocols such as China, Turchin [21]. The difficulties in modeling all these (interconnected) risks together are due to the fact that there is uncertainty in the communications, Leduc and Liu [13] and in the procedures themselves to be used. This is natural, given the novelty of the epidemiological risks that our societies are undergoing. There is a need to broaden the data used and apply new modeling techniques.

In responding to the COVID-19 epidemic, modelling is an essential tool for researchers and policy advisors to simulate the impact of various interventions or public health strategies, and to provide quantitative predictions of how interventions might affect population health in the future. In this analysis, we cannot leave out other factors such as geographical areas and different responses by region and between and within countries.

The last four years have seen the continued decline of global governance as illustrated in the loss of funding and influence of global organizations such as the World Health Organization (WHO), the United Nations (UN), and the International Monetary Fund (IMF). The spread of viral disease such as coronavirus that resulted in the COVID-19 pandemic can only be addressed through global cooperation of countries by strong multilateral organizations.

The recent research is still in its infancy and several elements are missing. The present work intends to map: what are the key connections? Until recently, much weight was attached to the economic and financial system. Today, other risks are more serious and manifest: epidemics, societal, technological, and geopolitical risks. Asking the question: What are the reasons for the differences between different geographical areas?

Table 1. New deaths per million and per capita GDP (all countries).

\begin{tabular}{|c|c|c|c|c|c|c|}
\hline Random-effects GLS regression & \multicolumn{6}{|c|}{ Number of obs $=57,546$} \\
\hline Group variable: country & \multicolumn{6}{|c|}{ Number of groups $=173$} \\
\hline R-sq: & \multicolumn{6}{|c|}{ Obs per group: } \\
\hline within $=0.0000$ & \multicolumn{6}{|l|}{$\min =53$} \\
\hline between $=0.2284$ & \multicolumn{6}{|l|}{$\operatorname{avg}=332.6$} \\
\hline \multirow[t]{2}{*}{ overall $=0.0403$} & \multicolumn{6}{|l|}{$\max =412$} \\
\hline & \multicolumn{6}{|c|}{ Wald chi2 $(1)=50.69$} \\
\hline $\operatorname{corr}\left(u_{-} \mathbf{i}_{,}, \mathbf{X}\right)=0$ (assumed) & \multicolumn{6}{|c|}{ Prob $>$ chi $2=0.0000$} \\
\hline new_deaths_p $\sim n$ & Coef. & Std. Err. & $\mathbf{z}$ & $\mathbf{P}>|\mathbf{z}|$ & \multicolumn{2}{|c|}{ [95\% Conf. Interval] } \\
\hline log_gdp_per_ca & .6016365 & .0845047 & 7.12 & 0.000 & .4360103 & .7672626 \\
\hline _cons & -4.271105 & .7885259 & -5.42 & 0.000 & -5.816587 & -2.725622 \\
\hline sigma_u & 1.328582 & & & & & \\
\hline sigma_e & 3.291859 & & & & & \\
\hline rho & $.1400734(\mathrm{f}$ & lance due to $\mathrm{u}$ i) & & & & \\
\hline
\end{tabular}

Table 2. Total deaths per million and per capita GDP (all countries).

\begin{tabular}{|c|c|c|c|c|c|c|}
\hline Random-effects GLS regression & \multicolumn{6}{|c|}{ Number of obs $=\mathbf{5 7 , 5 4 7}$} \\
\hline Group variable: country & \multicolumn{6}{|c|}{ Number of groups $=173$} \\
\hline R-sq: & \multicolumn{6}{|c|}{ Obs per group: } \\
\hline within $=0.0000$ & \multicolumn{6}{|l|}{$\min =53$} \\
\hline between $=0.2000$ & \multicolumn{6}{|l|}{$\operatorname{avg}=332.6$} \\
\hline \multirow[t]{2}{*}{ overall $=0.1008$} & \multicolumn{6}{|l|}{$\max =412$} \\
\hline & \multicolumn{6}{|c|}{ Wald chi2 $(1)=42.79$} \\
\hline $\operatorname{corr}\left(u_{-} \mathbf{i}_{1}, \mathbf{X}\right)=0$ (assumed) & \multicolumn{6}{|c|}{ Prob $>$ chi $2=0.0000$} \\
\hline total_deaths $\sim$ n & Coef. & Std. Err. & $\mathbf{z}$ & $\mathbf{P}>|\mathbf{z}|$ & \multicolumn{2}{|c|}{ [95\% Conf. Interval] } \\
\hline log_gdp_per_ca & 79.4941 & 12.15299 & 6.54 & 0.000 & 55.67468 & 103.3135 \\
\hline cons & -574.8456 & 113.3938 & -5.07 & 0.000 & -797.0935 & -352.5977 \\
\hline sigma_u & 192.53477 & & & & & \\
\hline sigma_e & 219.92155 & & & & & \\
\hline rho & .43389225 & riance due & & & & \\
\hline
\end{tabular}

\section{Methods}

\subsection{Stylized Facts}

Even taking into account possible difficulties in obtaining data, it is evident that rich countries were most affected by the pandemic. Schellekens and Sourrouille [28] document that despite the extensive spread of the virus, the mortality toll in 2020 were highly concentrated in high-income countries. Developed countries represent, numerically, the most of world inhabitants: 15 percent of the global 
population, but 79 percent of the pandemic's death toll. We find that the countries with the highest per capita incomes are the most demanding. While, within the G7, the population with the highest GDP per capita has a significant and negative coefficient with respect to deaths. Therefore: in the world, the pandemic affects rich countries more but, within them, the wealthy population is less affected.

Table 1 shows a positive and significant coefficient between new deaths per million and the log of per capita GDP of .6016365, and Table 2 shows a positive and significant coefficient between total deaths per million and the log of per capita GDP of 79.494 (data description is in the appendix). Regressions are run until the 31 January 2021, in order to avoid the vaccination effects.

\subsection{Thesis}

The question that this research seeks to understand is: Why, after an increase in restrictions, was there an increase in new COVID-19 cases? Board, G. P. M. reports $[1,2]$ Mukherjee [27] suggest that perhaps this is due to the inadequacy or uncertainty of new norms.

The research focuses on the G7 countries to understand how the restrictive regulations, summarized by the stringency index, have impacted the epidemic. The report analyses data for 184 countries in order to compare the findings.
To avoid confusing causality impacts, we have selected the end date of January 2021 for our data sample, i.e. to avoid the influence of the start of the vaccine injection schedule. We have also provided the data on excess mortality over historical averages to inform interpretation of variances between country reporting in Table 8 of the Appendix.

The analysis included several GLS regressions for panel data. As a result, stringent and time-varying policies have worsened the situation worldwide.

The following tables analyze the G7: new deaths and total deaths per million of inhabitants. The variables that exhibited multicollinearities have been dropped from the data set.

\subsection{Data Description}

The data are downloaded from the Oxford Martin School and Worldometers database. The frequency is daily and covers 184 countries starting from the first day of the epidemic until February 1, 2021.

In this way we get an unbalanced panel for different countries. The analyzes was performed with data that is certain for all countries: the total number of deaths and the number of new deaths per million inhabitants. In fact, the number of tests is a very variable and unreliable figure. There are countries that have conducted many tests and others that have many positive individuals but do not have many deaths.

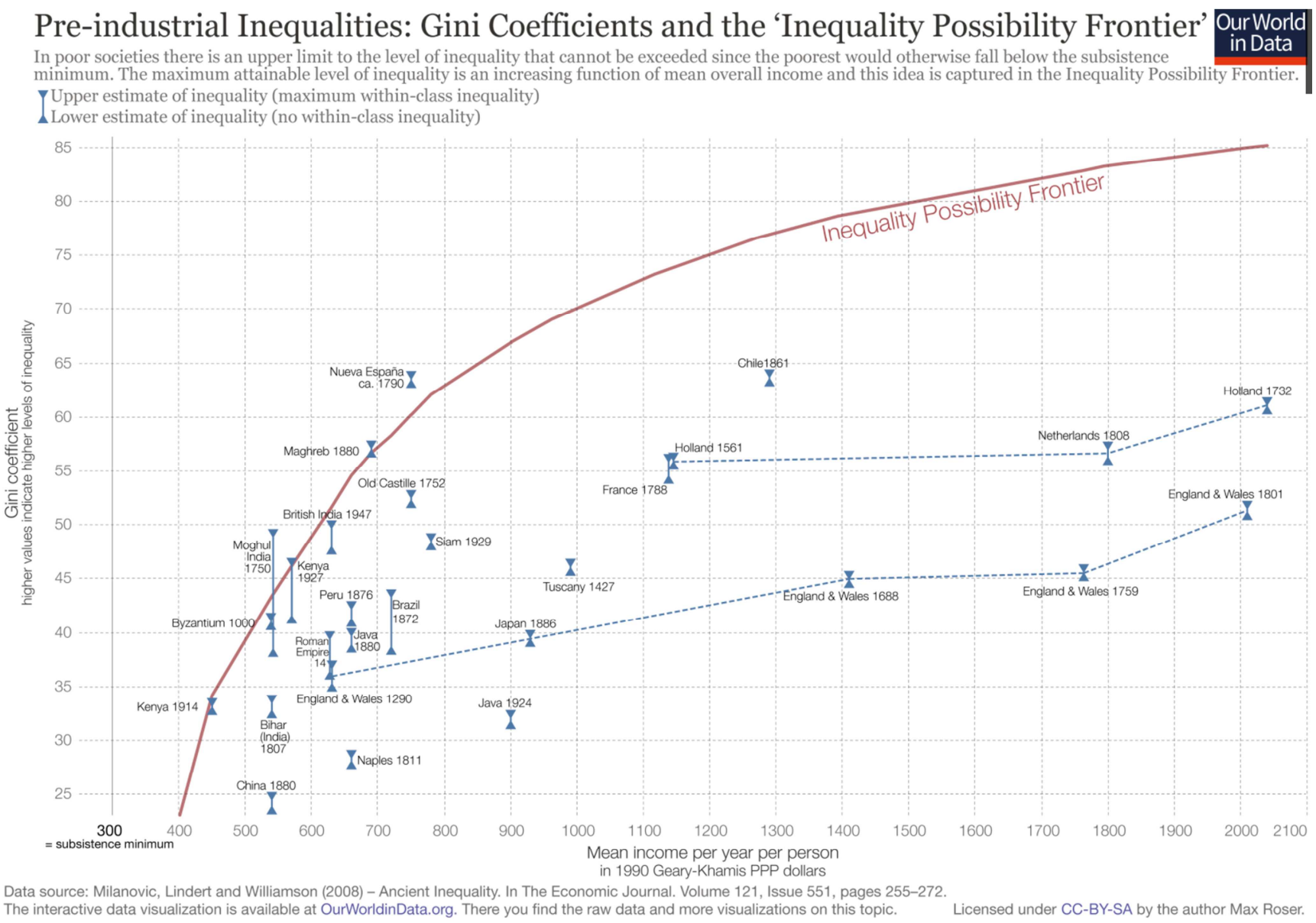

Figure 1. Estimates of Gini's impact by country. 


\section{Results}

\subsection{Disparity of Income and Wealth}

Intuitively, the COVID-19 pandemic numbers by country are not as predicted or expected. To further understand why this has happened we dig deeper into the segment of society that was most effected by the COVID-19 virus in 2020. Within affluent countries, reported cases and deaths were higher among socio-economic challenged populations Finch,
W. H., and Hernandez Finch, M. E [6]. This was supported by the number of deaths that are significantly positively influenced by the Gini index. The Gini index OECD [14] measures the extent to which the distribution of income (or, in some cases, consumption expenditure) among individuals or households within an economy deviates from a perfectly equal distribution. A Gini index of zero represents perfect equality and 100 , perfect inequality.

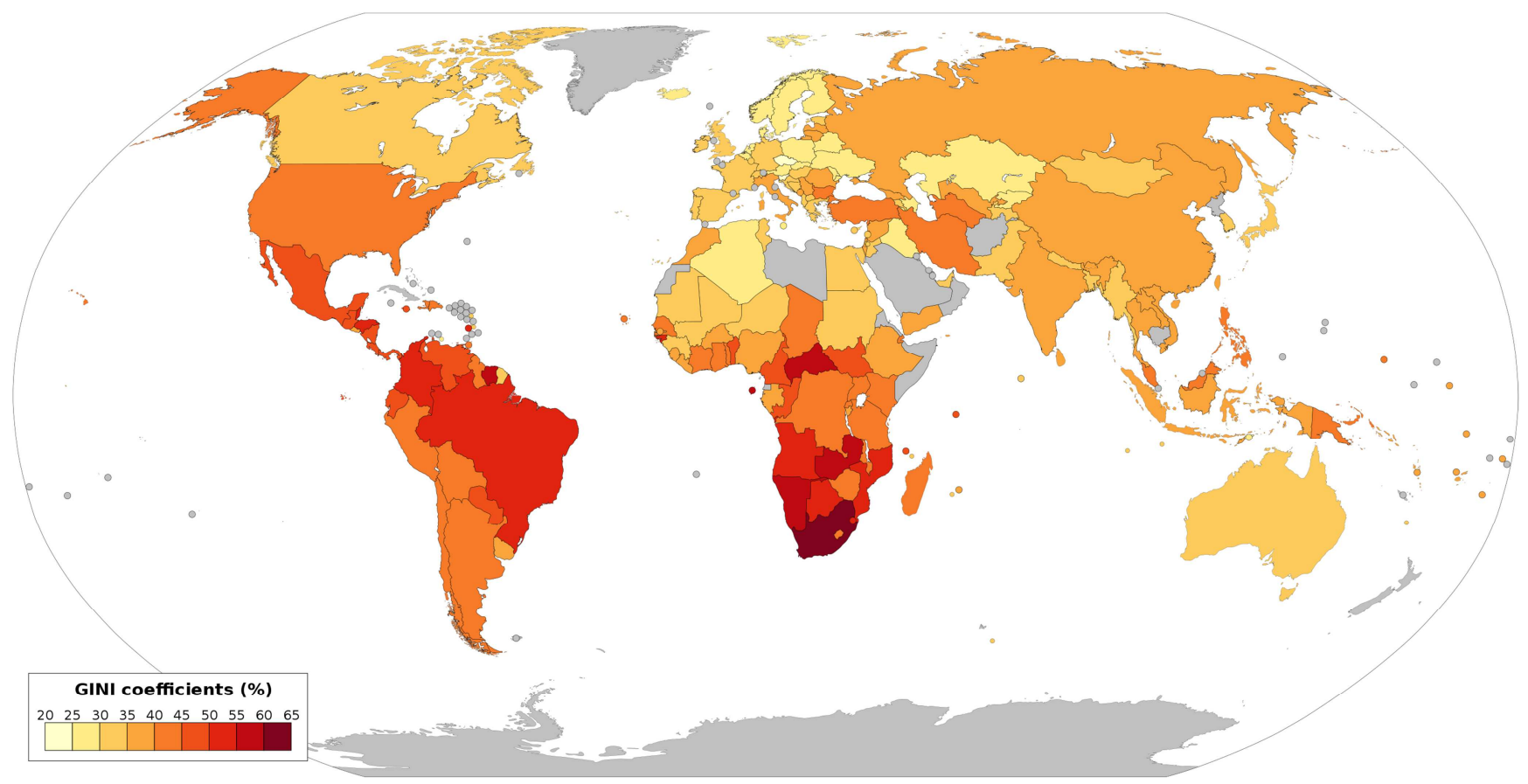

Figure 2. World map of the GINI coefficients by country (World Bank 2018).

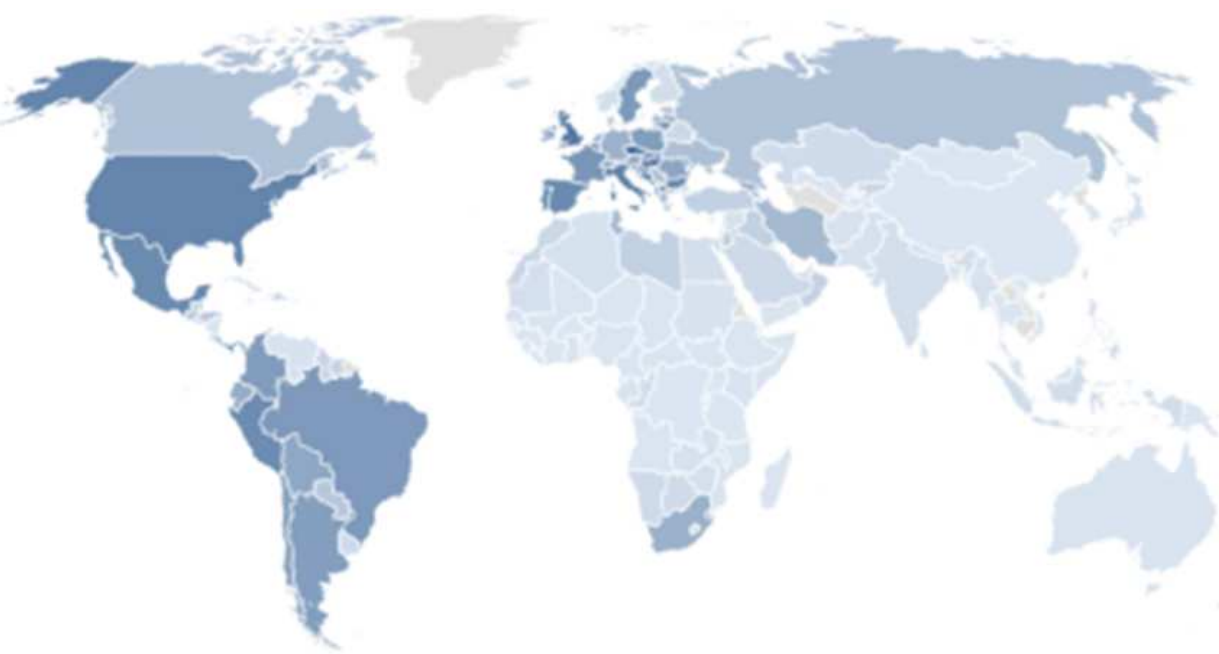

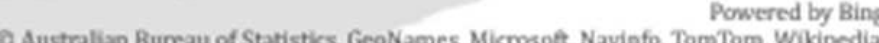

Figure 3. COVID-19 Deaths per 100,000 people. 
According to World Bank's Poverty and Shared Prosperity 2020 report [26], the Gini coefficient increases about 1.5 points in the five years following major epidemics, such as H1N1 (2009), Ebola (2014), and Zika (2016). The International Monetary Fund has estimated that the GINI index has increased about 3 points at the end of Q3, 2020 as a result of the COVID-19 pandemic, Cugat \& Narita [4]. The Word Bank's reported that COVID-19 was likely to push between 88 and 115 million people into extreme poverty. Figure 1 shows Pre-industrial inequalities: Gini coefficients, and the Inequality Possibility Frontier. The estimates are prudent because they were made before COVID-19 but still capture the effects of previous epidemics as highlighted by the World Bank.

In Figure 2 the country GINI index for 2018, World Bank [25] compares to Figure 3, John Hopkins [12] the daily COVID-19 deaths 100,000 people in 2020. The data illustrates that in many countries Gini score are an indicator of increased risk for COVID-19 exposure and potential severity.

\subsection{New COVID-19 Deaths Rise After Restrictions Announced}

The country Gini score sets the foundation for further investigation into the question of: Why? after an increase in restrictions, was there an increase in new COVID-19 deaths?
The results in Tables 3 and 4 illustrate the Generalized Least Squares (GLS) regression to identify the explain ability of the COVID-19 deaths based upon stringency lag of 20 days.

\subsection{Stringency Index}

The next element of the research compared the implications of the stringency of restrictions implemented to the number of deaths. Which produced the finding that there is an increase in deaths after there is an increase in restrictions for all countries. Table 3 shows that new deaths increased with respect to the stringency index which demonstrates the significant positive correlation of 0.0145 with a standard error of 0.0007 .

Table 4 compares the daily country COVID-19 Total deaths per million people to the stringency index which demonstrates the significant positive correlation of 0.83 with a standard error of 0.04 . This positive correlation is counterintuitive, as expectations of implementing stricter restrictions would cause the number of new deaths to decline. The significant positive correlation score is a conservative estimate due to the fact that the data set does not include excess mortality deaths which would increase correlations of the COVID-19 to new and total deaths to stringency index. Data and graphical illustration of excess mortality shown in Appendix Table 8: Excess mortality P-scores, all ages percent.

Table 3. New deaths per million Stringency Index 0 rules - 100 total lock down Stringency Lag number of 20 days All countries.

\begin{tabular}{|c|c|c|c|c|c|c|}
\hline Random-effects GLS regression & \multicolumn{6}{|c|}{ Number of obs $=52,090$} \\
\hline Group variable: country & \multicolumn{6}{|c|}{ Number of groups $=167$} \\
\hline R-sq: & \multicolumn{6}{|c|}{ Obs per group: } \\
\hline within $=0.0094$ & \multicolumn{6}{|l|}{$\min =42$} \\
\hline between $=0.5232$ & \multicolumn{6}{|c|}{ avg $=311.9$} \\
\hline \multirow[t]{2}{*}{ overall $=0.0918$} & \multicolumn{6}{|l|}{$\max =378$} \\
\hline & \multicolumn{6}{|c|}{ Wald chi2(15) = 677.65} \\
\hline $\operatorname{corr}\left(u_{-} \mathbf{i}, \mathbf{X}\right)=\mathbf{0}$ (assumed) & \multicolumn{6}{|c|}{ Prob $>$ chi $2=0.0000$} \\
\hline new_deaths_pe $\sim$ n & Coef. & Std. Err. & $\mathbf{z}$ & $\mathbf{P}>|\mathbf{z}|$ & \multicolumn{2}{|c|}{ [95\% Conf. Interval] } \\
\hline reproduction_ $\sim \mathrm{e}$ & -.4283151 & .0365402 & -11.72 & 0.000 & -.4999326 & -.3566977 \\
\hline stringency_20 g & .0145087 & .0007886 & 18.40 & 0.000 & .012963 & .0160543 \\
\hline population & $-6.86 e-11$ & $4.91 \mathrm{e}-10$ & -0.14 & 0.889 & $-1.03 \mathrm{e}-09$ & $8.93 \mathrm{e}-10$ \\
\hline median_age & .0185347 & .0276352 & 0.67 & 0.502 & -.0356294 & .0726988 \\
\hline aged_65_older & -.0922993 & .0707718 & -1.30 & 0.192 & -.2310094 & .0464109 \\
\hline aged_70_older & .1997357 & .0824042 & 2.42 & 0.015 & .0382266 & .3612449 \\
\hline log_gdp_per_ca & .5189546 & .1326864 & 3.91 & 0.000 & .258894 & .7790152 \\
\hline cardiovasc_de $\sim$ e & -.0000826 & .0008718 & -0.09 & 0.925 & -.0017912 & .001626 \\
\hline diabetes_prev $\sim$ e & -.0151876 & .0246423 & -0.62 & 0.538 & -.0634855 & .0331104 \\
\hline female_smokers & .0808222 & .0145485 & 5.56 & 0.000 & .0523076 & .1093368 \\
\hline male_smokers & -.0138554 & .0056565 & -2.45 & 0.014 & -.0249419 & -.002769 \\
\hline handwashing_f $\sim$ s & .0042947 & .00254 & 1.69 & 0.091 & -.0006836 & .009273 \\
\hline hospital_beds $\sim$ d & -.0065051 & .0465413 & -0.14 & 0.889 & -.0977244 & .0847142 \\
\hline life_expectancy & .0242283 & .0141512 & 1.71 & 0.087 & -.0035075 & .0519642 \\
\hline human_develop $\sim$ X & -4.82414 & 1.224384 & -3.94 & 0.000 & -7.223889 & -2.424391 \\
\hline _cons & -3.590446 & 1.208734 & -2.97 & 0.003 & -5.959522 & -1.22137 \\
\hline sigma_u & \multicolumn{6}{|l|}{.95980656} \\
\hline sigma_e & \multicolumn{6}{|l|}{3.2377239} \\
\hline rho & \multicolumn{6}{|c|}{.08078059 (fraction of variance due to $u \_\mathrm{i}$ ) } \\
\hline
\end{tabular}


Table 4. Total deaths per million.

\begin{tabular}{|c|c|c|c|c|c|c|}
\hline Random-effects GLS regression & \multicolumn{6}{|c|}{ Number of obs $=52,090$} \\
\hline Group variable: country & \multicolumn{6}{|c|}{ Number of groups $=167$} \\
\hline R-sq: & \multicolumn{6}{|c|}{ Obs per group: } \\
\hline within $=0.0524$ & \multicolumn{6}{|l|}{$\min =42$} \\
\hline between $=0.4551$ & \multicolumn{6}{|l|}{ avg $=311.9$} \\
\hline overall $=\mathbf{0 . 2 7 5 9}$ & \multicolumn{6}{|l|}{$\max =378$} \\
\hline & \multicolumn{6}{|c|}{ Wald chi2 $(15)=3016.00$} \\
\hline $\operatorname{corr}\left(\mathbf{u}_{-} \mathbf{i}, \mathbf{X}\right)=\mathbf{0}$ (assumed) & \multicolumn{6}{|c|}{ Prob $>$ chi $2=0.0000$} \\
\hline total deaths $\sim$ n & Coef. & Std. Err. & $\mathbf{z}$ & $\mathbf{P}>|\mathbf{z}|$ & \multicolumn{2}{|c|}{ [95\% Conf. Interval] } \\
\hline reproduction_ $\sim \mathrm{e}$ & -90.79504 & 1.883012 & -48.22 & 0.000 & -94.48568 & -87.10441 \\
\hline stringency_20 $\sim \mathrm{g}$ & .8351974 & .0406861 & 20.53 & 0.000 & .7554542 & .9149407 \\
\hline population & $4.77 \mathrm{e}-08$ & $6.68 \mathrm{e}-08$ & 0.71 & 0.475 & $-8.32 \mathrm{e}-08$ & $1.79 \mathrm{e}-07$ \\
\hline median_age & -.319654 & 3.754007 & -0.09 & 0.932 & -7.677373 & 7.038065 \\
\hline aged_ 65 _older & -10.66894 & 9.613712 & -1.11 & 0.267 & -29.51147 & 8.173585 \\
\hline aged_70_older & 20.34791 & 11.20206 & 1.82 & 0.069 & -1.607737 & 42.30355 \\
\hline log_gdp_per_ca & 111.2287 & 18.03609 & 6.17 & 0.000 & 75.87857 & 146.5787 \\
\hline cardiovasc_de $\sim$ e & -.0551732 & .1183989 & -0.47 & 0.641 & -.2872308 & .1768843 \\
\hline diabetes_prev $\sim$ e & -6.489726 & 3.341425 & -1.94 & 0.052 & -13.0388 & .0593462 \\
\hline female_smokers & 8.36857 & 1.971421 & 4.24 & 0.000 & 4.504656 & 12.23248 \\
\hline male_smokers & -1.966119 & .7684485 & -2.56 & 0.011 & -3.472251 & -.4599879 \\
\hline handw̄ashing $f \sim s$ & .5800273 & .3451555 & 1.68 & 0.093 & -.096465 & 1.25652 \\
\hline hospital_beds $\sim$ d & -3.720021 & 6.311851 & -0.59 & 0.556 & -16.09102 & 8.650979 \\
\hline life_expectancy & 8.861599 & 1.923916 & 4.61 & 0.000 & 5.090793 & 12.6324 \\
\hline human_develop $\sim \mathrm{x}$ & -961.9481 & 166.5152 & -5.78 & 0.000 & -1288.312 & -635.5843 \\
\hline _cons & -806.1726 & 164.236 & -4.91 & 0.000 & -1128.069 & -484.2759 \\
\hline sigma_u & 132.55746 & & & & & \\
\hline sigma_e & 165.78427 & & & & & \\
\hline rho & .38999285 & riance due & & & & \\
\hline
\end{tabular}

\subsection{Stringency Lag}

With this counter-intuitive result on the Stringency Index the research turned to examine the effectiveness of stringency measures. The leading indicator was found to be the stringency lag index. The stringency index correlated with the stringency lag point to the effectiveness of policies being positively correlated due to a lag in implementation and partial application. Moreover, the uncertainty or the variability of the stringency index has a negative impact on mortality. (The longer the stringency lag, the higher the number of deaths.)

Tables 5 compares the daily country COVID-19 deaths per million people by stringency index to the stringency lag index which demonstrates the significant positive correlation of new and total deaths for all countries. This positive correlation is surprising, as expectations of a lag in implementing stricter restrictions have seem to have caused or encouraged behavior that has increased the probability of exposure and resulted in an increase in the number of new deaths. The two stringency index comparisons, reported in Table 7, are:

a. G7 countries have a significant coefficient of 3.27 between stringency lags of 20 days, correlation to COVID-19 total deaths by millions of people.

b. The average world country has a coefficient of 0.369 between stringency lags of 5 days, correlation to COVID-19 total deaths by millions of people.

\section{The Effectiveness of Restrictive Stringency Measures Declines as the Stringency Lag Increases in G7 Countries}

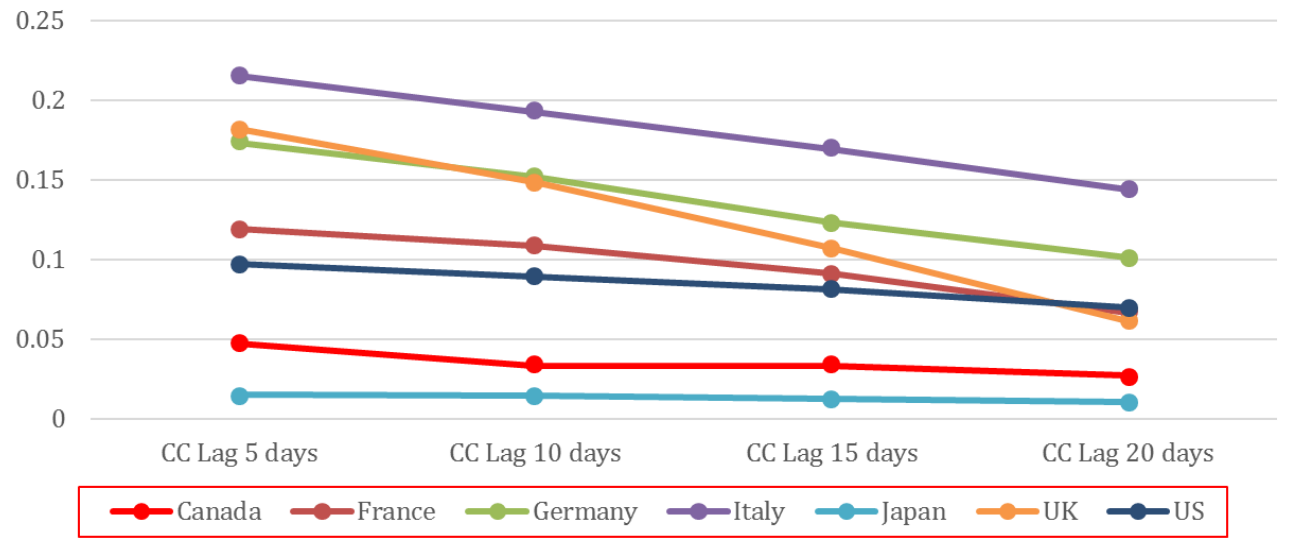

Figure 4. G7 Country Correlation Coefficient for Stringency Lag and Number of COVID-19 Deaths. 
The analysis was performed on GLS regressions for four different stringency lags: 5, 10,15 and 20 days. Results are significant and they confirm the failure of stringency policies in decreasing the new deaths per million of inhabitants. The Stringency Policy of the G7 countries was negatively affected by the increase of the stringency lag. The results in Figure 4 of correlation coefficient lag for the G7 countries overall in days: $5,10,15,20$ demonstrate a decrease in effectiveness as the influence of the stringency upon total number of deaths as the number of days of lag increase. All countries showed a decrease in effectiveness of Restrictive Stringency Measures as the Stringency Lag Increased.
Canada had the greatest decline in effectiveness of restrictions between 5-to-10 days, and 15-to-20-day stringency lag. While the UK and Italy had a consistent decline in effectiveness of restrictions between 5-to-20-day stringency lag. Many countries including Canada, the UK, and Italy have entered the third wave with the variants spreading at a faster rate, and in some cases more serious outcomes. These findings support the epidemiologist recommendation of enforcing stringency restrictions with a minimum stringency lag.

Data in Table 5 summarized from regression analysis found in the Appendix: New deaths per million for the G7, Stringency Index 0 rules - 100 total lock-downs, Stringency.

Table 5. Correlation Coefficient for Stringency Lag and Number of COVID-19 Deaths.

\begin{tabular}{|c|c|c|c|c|}
\hline Country & CC Lag 5 days & CC Lag 10 days & CC Lag 15 days & CC Lag 20 days \\
\hline Canada & 0.0469587 & 0.0330230 & 0.0330231 & 0.0268953 \\
\hline France & 0.1191952 & 0.1086463 & 0.0912500 & 0.0667217 \\
\hline Germany & 0.1735164 & 0.1519831 & 0.1234327 & 0.1011956 \\
\hline Italy & 0.2153415 & 0.1929895 & 0.1695471 & 0.1436887 \\
\hline Japan & 0.0149777 & 0.0142467 & 0.0122697 & 0.0106237 \\
\hline UK & 0.1822433 & 0.1485170 & 0.1075094 & 0.0608768 \\
\hline US & 0.0975260 & 0.0892139 & 0.0813467 & 0.0695305 \\
\hline
\end{tabular}

\subsection{Power Distance Index}

To further understand or interpret the resultant reaction or behavior to the restrictions (stringency) and the implications in the speed of enforcement (stringency lag) in the G7 and globally, the research compared countries with similar stringency and stringency lags that have diverging COVID-19 results. Countries heterogeneity is a key factor in COVID-19 policy governance design as remarked Haug et al [8]. They assess how the effectiveness of Nonpharmaceutical Interventions (NPIs) depend on the local context such as timing of their adoption. This opens the way for forecasting the effectiveness of future interventions using hypothetical scenarios. In contrast to Haug et al [8], we actually tested what happened differently in relation to the various geographic areas. Our work is not "what if" but demonstrates the differences between countries with their cultures and consequential differences in legislation, habits, and mentality of the people.
This difference among individuals within a country is studied by the "Power Distance" by Hofstede, G. [10]. Hofstede's Power distance Index (PDI) measures the extent to which the less powerful members of organizations and institutions (like the family) accept and expect that power is distributed unequally. This represents inequality (more versus less), but defined from below, not from above. It suggests that a society's level of inequality is endorsed by the followers as much as by the leaders. A higher PDI score may indicate a higher acceptance and following of restrictions due to COVID-19. Figure 5 compares the daily country COVID19 deaths per million people to the PDI. In isolation, a positive influence is not totally surprising, as stricter restrictions do not seem to have been enough to encouraged behavior that would decreased the probability of exposure and in-turn have resulted in an increase in the number of new cases in countries where a government's power to impose restrictions is not accepted.

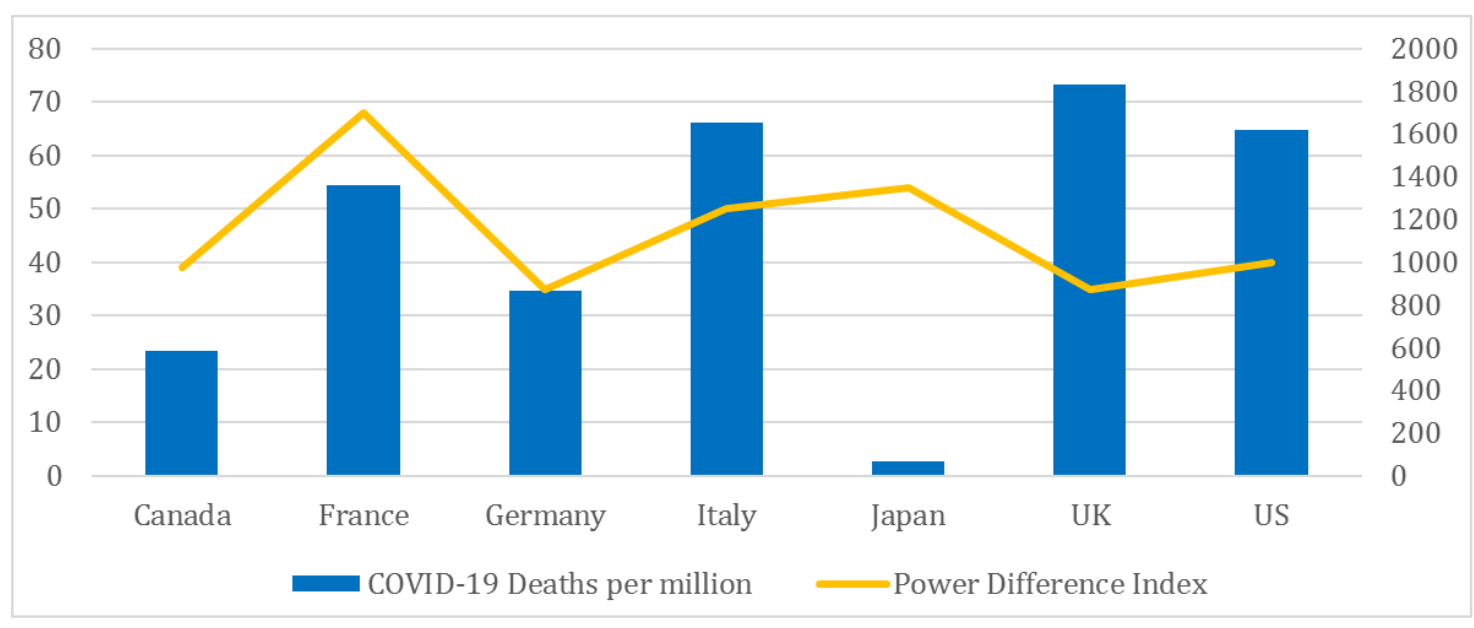

Figure 5. Power Difference Index compared to COVID-19 Deaths per Million. 


\section{Discussion}

\subsection{Improve Policy Management}

On March 13, 2020, Dr. Ryan, WHO, stated "Be fast, have no regrets. You must be the first mover. The virus will always get you if you don't move quickly." Global results have unfortunately proven Dr. Ryan correct.

These important findings seek the key to improve policy management of the virus worldwide. These findings support the urgency for policy makers to understand and enforce the stringency of regulations, weighted heavily by impact that the stringency lag will make on the effectiveness of the restriction, in relation to the willingness of inhabitants of their countries to follow the restrictions as indicative of the countries Power Distance index. Limiting the stringency lag of their policies to increase the effectiveness in reducing the transmission of COVID-19 and the resulting number and severity of new cases is supported by the positive correlation of the stringency lag to the number of COVID-19 deaths per million.

\subsection{Example and Implications of Stringency Lag}

The Stringency Lag was observed in the early days, predeclaration of the pandemic, there was a lag between symptoms of the virus, spread, declaration, and implementation of border closures, lockdowns, and travel restrictions. With the identification of the COVID-19 variants the implications of a stringency lags are continuing to be identified.

\subsubsection{Wuhan, Dec 2019}

The initial stringency lag was witnessed even before the world realized that a pandemic was on their doorstep. In Wuhan, Dec 30, 2019, Chinese doctors warn of contagious infection, information is shared January 11, 2020 on WeChat, Dr. Zhangs uploaded the viruses sequencing to Global online library of genetic data. Not until Jan 23, 2020 did Xi Jennings seal off Wuhan. One early study projected that China could have reduced the total number of cases by $66 \%$ had officials acted a week earlier, and $95 \%$ if actions were taken 3 week earlier, Lai, S. [29].

As we examine the trends that are related to the spread of viral disease. COVID-19 was potentially made worse by the interstate conflict between the US and China, as the US pulled the last US doctors from inside the Chinese CDC in July 2019, Buckley et al [3].

\subsubsection{UK, September 2020}

Another example of the effect of the Stringency Lag is the COVID-19 variant B117 first identified in the UK. It was identified September 20,2020 and by the week ending December 9, 2020, B117 accounted for $62 \%$ of the infections in London. It took until December 20th for travel restrictions to be announced. Travel restrictions were first enforced by other countries banning flights from the UK as early as December 21. However, there was a lag of flight restrictions by the UK for air travel out of the UK. By January 29, 2021, 70 countries have shown both imported and local transmission cases of the new strains of coronavirus, O'Tolle and Hill [15].

\subsubsection{Canada, January 2021}

The spread of the COVID-19 variants makes the stringency lag finding and the call to immediate action even greater. The UK variant entered a Barrie, Ontario Long-term care home identified on January $8^{\text {th }}$, by January $20^{\text {th }}$ the variant had spread to most of the 130 residents, 69 staff, and two visitors. Nineteen people had already died and six were in hospital.

Newfoundland, which had all but isolated the province, previously had almost no COVID-19 cases. Previous to February 5, 2021 when the COVID-19 UK variant was identified the province had only a total of 412 cases. In the next 15 days, 256 new cases have been reported, over half of the entire case load to date. The increase transmission of the new variants increases the urgency in immediately reducing the stringency lag.

\subsection{Impact of Stringency and Stringency Lag}

The impact of the inter-relationship between the Stringency Index, Stringency Lag, and the Power Difference index across countries can be seen not only in the number of COVID-19 deaths but also on many other indicators. The stringency lag affected the increase in unemployment between $10-90 \%$ dependent upon industry and geography Falk et al. [5]; the overall decline by country of GDP between $2-10 \%$, Jackson et al [11]; the increase in mental health cases reported by the CDC, averaging an increase of adults showing symptoms of anxiety or depression disorder from $11 \%$ to $42 \%$, Richter [16]; and increase of disparity of income and wealth demonstrated by the share of income going to the top $1 \%$ in the past year doubling, Goldin \& Maggah [24]. The International Labor Organization estimated that the restrictions on businesses and public life destroyed $8.8 \%$ of all work hours around the world last year. That is equivalent to 255 million full-time jobs - quadruple the impact of the financial crisis over a decade ago. The drop in work translates to a loss of $\$ 3.7$ trillion USD in income globally - what Ryder called an "extraordinary figure" - with women and young people taking the biggest hits by Jan 26, 2021.

These economic and societal implications are also the result of an increased stringency lag which policy makers must take into consideration by reducing the stringency lag to reduce the new deaths from COVID-19 and which will in the short-term reduce the strain on hospitals, in the medium-term lead to a shorter complete lockdown periods, and a faster return to full employment and reduced mental health effects. The takeaway is, that where pandemic restrictions are concerned, it is better to rip-off the Band-Aid quickly, that is to implement quickly and completely restrictions without lag or delay.

\subsection{The Heterogeneity Among Areas}

This section shows the supporting results. Several GLS regressions were run for panel data, in order to capture the most important and common results for all countries. In fact, as highlighted by international reports, Board, G. P. M. [1], 
[2], the management of COVID-19 has lacked common and uniform policies with agreements between countries to stem the epidemic. As a result, stringent and time-varying policies have worsened the situation worldwide. The graph in Figure 6 and the supporting data in the appendix: Tab 15 shows how each macro area has significantly different results.

\section{Conclusions}

The primary conclusions are a) the ineffectiveness or inappropriateness of the virus containment stringency and stringency lag measures, b) The confirmation that COVID-19 affected the countries with the highest per capita income was increased by the ineffectiveness of restrictions due to stringency lags.

It is important to highlight how the results are made even more robust by the problem that the data used in the estimates are the minimum number of cases, due to the underestimation of deaths due to the excess mortality reported in 2020. In the appendix, we have illustrated: Excess mortality during the COVID-19 pandemic.

These findings are key to improve the future policy management of the virus and variants. The Delta plus and Lambda variant's increased transmissibility and potential vaccine resistance increases the urgency for policy makers to understand and immediately enforce the stringency of regulations in consideration of their countries Power Balance index, and to reduce the stringency lag of their policies to increase the effectiveness in reducing the transmission of COVID-19. Follow-up research will further examine and compare the effects of the COVID-19 variants, vaccine distribution, COVID-19 deaths and public policy measures.

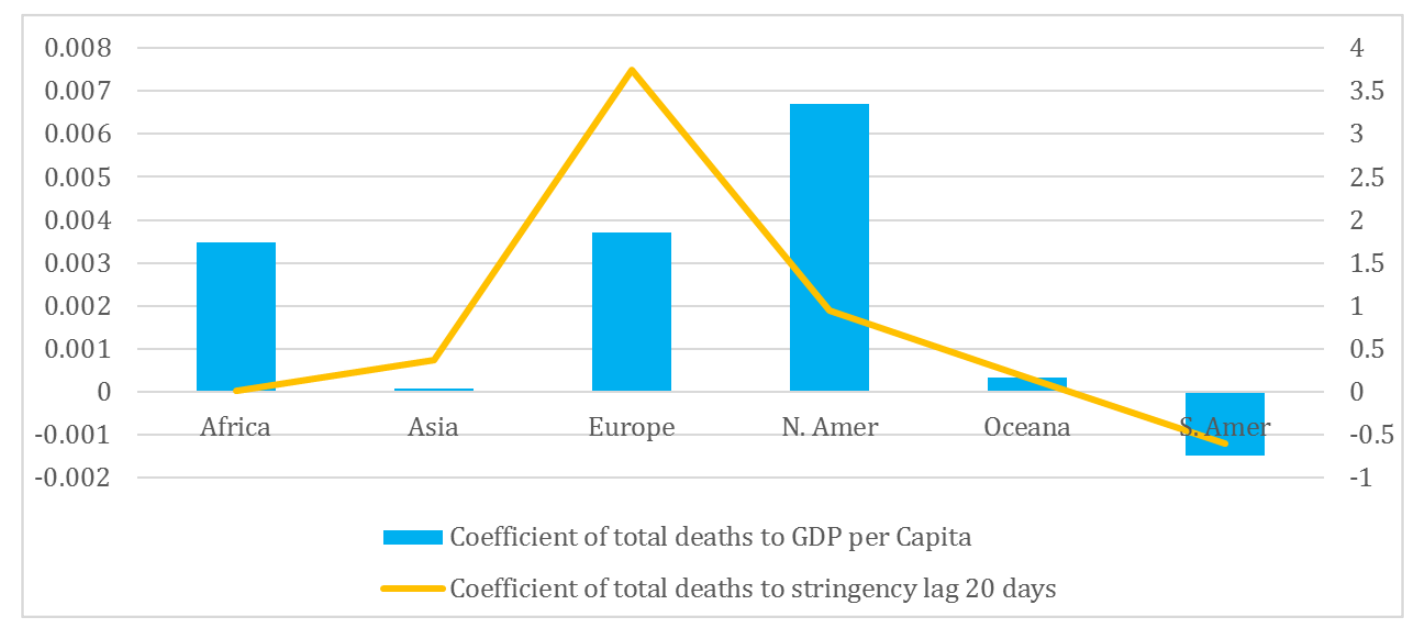

Figure 6. Coefficient of Total COVID-19 deaths to 20-day stringency lag and GDP per Capita.

\section{Appendix}

Table 6. Description of Variables.

\begin{tabular}{|c|c|}
\hline Varia & \\
\hline new_deaths_per_million & Daily new deaths per million of inhabitants \\
\hline stringency_20lag & Stringency index: from 0 rules to 100 lockdown with 20 days of lag \\
\hline total_deaths_per_million & Total deaths per million of inhabitants \\
\hline & The indicator that measures in which conditions generations are replaced. \\
\hline reproduction_rate & $\begin{array}{l}\text { It is computed by establishing a ratio between the number of daughters and that of their mothers, independently from } \\
\text { effects due to population structure. This calculation can be made by taking into account the mortality (net reproduction } \\
\text { rate) or in the absence of mortality (crude reproduction rate). In practice this rate is usually computed for a given year or } \\
\text { period, in that case it measures the conditions of the moment in terms of reproduction }\end{array}$ \\
\hline population_density & Measured by the number of human inhabitants per square kilometer \\
\hline median_age & $\begin{array}{l}\text { Age that divides the population in two parts of equal size, that is, there are as many persons with ages above the median as } \\
\text { there are with ages below the median }\end{array}$ \\
\hline aged_65_older & People older than 65 and less than 70 \\
\hline aged_70_older & People older than 70 \\
\hline log_gdp_per_ca & Log of gdp per capital \\
\hline cardiovasc death rate & The annual number of deaths from cardiovascular diseases per 100000 people \\
\hline diabetes_prevalence & The percentage of people ages $20-79$ who have type 1 or type 2 diabetes \\
\hline female_smokers & $\begin{array}{l}\text { The share of women aged } 15 \text { years and older who smoke any form of tobacco, including cigarettes, cigars, pipes or any } \\
\text { other smoked tobacco products. Data include daily and non-daily or occasional smoking. }\end{array}$ \\
\hline male_smokers & $\begin{array}{l}\text { The share of male aged } 15 \text { years and older who smoke any form of tobacco, including cigarettes, cigars, pipes or any other } \\
\text { smoked tobacco products. Data include daily and non-daily or occasional smoking. }\end{array}$ \\
\hline handwashing facilities & Population with basic handwashing facilities at home (\%) \\
\hline hospital beds per thousand & Hospital beds (per 1000 people) from The World Bank \\
\hline life expectancy & Estimate of the average number of additional years that a person of a given age can expect to live \\
\hline
\end{tabular}




\section{Variables description}

human_development_index

The Human Development Index (HDI) is a summary measure of key dimensions of human development: a long and healthy life, a good education, and having a decent standard of living

We perform GLS regressions for different lags: 5, 10, 15 and 20 days. Results are significant and they confirm the failure of stringency policies in decreasing the new deaths per million of inhabitants.

Table 7. New deaths per million for the G7.

Stringency Index 0 rules - 100 total lock down Stringency Lag number of 5 days.

Canada

\begin{tabular}{|c|c|c|c|c|c|}
\hline Source & SS & df & MS & \multicolumn{2}{|l|}{ Number of obs $=329$} \\
\hline & & & & \multicolumn{2}{|l|}{$F(1,327)=44.32$} \\
\hline Model & 98.6815349 & 1 & 98.6815349 & \multicolumn{2}{|l|}{ Prob $>F=0.0000$} \\
\hline Residual & 728.161958 & 327 & 2.22679498 & \multicolumn{2}{|l|}{ R-squared $=0.1193$} \\
\hline & & & & \multicolumn{2}{|l|}{ Adj R-squared = 0.1167} \\
\hline Total & 826.843493 & 328 & 2.52086431 & \multicolumn{2}{|l|}{ Root MSE = 1.4922 } \\
\hline new_deaths_pe $\sim$ n & Coef. & Std. Err. & $\mathbf{t}$ & {$[95 \%$ Conf } & \\
\hline stringency_5lag & .0469587 & .007054 & 6.66 & .0330817 & .0608357 \\
\hline cons & -1.483953 & .4725702 & -3.14 & -2.413614 & -.5542915 \\
\hline
\end{tabular}

France

\begin{tabular}{|c|c|c|c|c|c|c|}
\hline Source & SS & df & MS & \multicolumn{3}{|c|}{ Number of obs $=352$} \\
\hline & & & & \multicolumn{3}{|c|}{$F(1,350)=127.51$} \\
\hline Model & 1901.79139 & 1 & 1901.79139 & \multicolumn{3}{|c|}{ Prob $>F=0.0000$} \\
\hline Residual & 5220.25352 & 350 & 14.9150101 & \multicolumn{3}{|c|}{ R-squared $=0.2670$} \\
\hline & & & & \multicolumn{3}{|c|}{ Adj R-squared = 0.2649} \\
\hline Total & 7122.04491 & 351 & 20.2907262 & \multicolumn{3}{|c|}{ Root MSE = 3.862} \\
\hline new_deaths_pe $\sim$ n & Coef. & Std. Err. & $\mathbf{t}$ & $\mathbf{P}>|\mathbf{t}|$ & {$[95 \%$ Cont } & \\
\hline stringency_5lag & .1191952 & .0105558 & 11.29 & 0.000 & .0984345 & .1399559 \\
\hline cons & -3.984215 & .6785171 & -5.87 & 0.000 & -5.318699 & -2.649731 \\
\hline
\end{tabular}

Germany

\begin{tabular}{|c|c|c|c|c|c|c|}
\hline Source & SS & df & MS & \multicolumn{3}{|c|}{ Number of obs $=329$} \\
\hline & & & & \multicolumn{3}{|c|}{$F(1,327)=218.13$} \\
\hline Model & 1539.28506 & 1 & 1539.28506 & \multicolumn{3}{|c|}{ Prob $>F=0.0000$} \\
\hline Residual & 2307.55672 & 327 & 7.05674836 & \multicolumn{3}{|c|}{ R-squared $=0.4001$} \\
\hline & & & & \multicolumn{3}{|c|}{ Adj R-squared $=\mathbf{0 . 3 9 8 3}$} \\
\hline Total & 3846.84177 & 328 & 11.7281761 & \multicolumn{3}{|c|}{ Root MSE $=2.6565$} \\
\hline new_deaths_pe $\sim$ n & Coef. & Std. Err. & $\mathbf{t}$ & $\mathbf{P}>|\mathbf{t}|$ & {$[95 \%$ Con } & \\
\hline stringency_5lag & .1735164 & .0117485 & 14.77 & 0.000 & .1504041 & .1966286 \\
\hline cons & -8.880281 & .7560035 & -11.75 & 0.000 & -10.36753 & -7.393037 \\
\hline
\end{tabular}

Italy

\begin{tabular}{|c|c|c|c|c|c|c|}
\hline Source & SS & df & MS & \multicolumn{3}{|c|}{ Number of obs $=346$} \\
\hline & & & & \multicolumn{3}{|c|}{$F(1,344)=610.93$} \\
\hline Model & 4362.39426 & 1 & 4362.39426 & \multicolumn{3}{|c|}{ Prob $>F=0.0000$} \\
\hline Residual & 2456.36392 & 344 & 7.1405928 & \multicolumn{3}{|c|}{ R-squared $=0.6398$} \\
\hline & & & & \multicolumn{3}{|c|}{ Adj R-squared $=0.6387$} \\
\hline Total & 6818.75819 & 345 & 19.7645165 & \multicolumn{3}{|c|}{ Root MSE $=2.6722$} \\
\hline new_deaths_pe $\sim$ n & Coef. & Std. Err. & $\mathbf{t}$ & $\mathbf{P}>|\mathbf{t}|$ & {$[95 \%$ Con } & \\
\hline stringency_5lag & .2153415 & .0087123 & 24.72 & 0.000 & .1982054 & .2324776 \\
\hline cons & -10.17694 & .6003652 & -16.95 & 0.000 & -11.35779 & -8.996093 \\
\hline
\end{tabular}

Japan

\begin{tabular}{|c|c|c|c|c|c|c|}
\hline Source & SS & df & MS & \multicolumn{3}{|c|}{ Number of obs $=354$} \\
\hline & & & & \multicolumn{3}{|c|}{$F(1,352)=177.83$} \\
\hline Model & 5.29906023 & 1 & 5.29906023 & \multicolumn{3}{|c|}{ Prob $>$ F $=0.0000$} \\
\hline Residual & 10.4888523 & 352 & .029797876 & \multicolumn{3}{|c|}{ R-squared = 0.3356} \\
\hline & & & & \multicolumn{3}{|c|}{ Adj R-squared = 0.3338} \\
\hline Total & $\mathbf{1 5 . 7 8 7 9 1 2 5}$ & 353 & .044724965 & \multicolumn{3}{|c|}{ Root MSE =.17262 } \\
\hline new_deaths_pe $\sim$ n & Coef. & Std. Err. & $t$ & $\mathbf{P}>|\mathbf{t}|$ & {$[95 \%$ Con } & \\
\hline stringency_5lag & .0149777 & .0011232 & 13.34 & 0.000 & .0127688 & .0171866 \\
\hline cons & -.4233705 & .0423899 & -9.99 & 0.000 & -.5067398 & -.3400013 \\
\hline
\end{tabular}


United Kingdom

\begin{tabular}{|c|c|c|c|c|c|c|}
\hline Source & SS & df & MS & \multicolumn{3}{|c|}{ Number of obs $=332$} \\
\hline & & & & \multicolumn{3}{|c|}{$F(1,330)=102.15$} \\
\hline Model & 2469.57534 & 1 & 2469.57534 & \multicolumn{3}{|c|}{ Prob $>$ F $=0.0000$} \\
\hline Residual & 7978.24853 & 330 & 24.1765107 & \multicolumn{3}{|c|}{ R-squared $=0.2364$} \\
\hline & & & & \multicolumn{3}{|c|}{ Adj R-squared $=0.2341$} \\
\hline Total & 10447.8239 & 331 & 31.5644225 & \multicolumn{3}{|c|}{ Root MSE $=4.917$} \\
\hline new_deaths_pe $\sim$ n & Coef. & Std. Err. & $\mathrm{t}$ & $\mathbf{P}>|\mathbf{t}|$ & \multicolumn{2}{|c|}{ [95\% Conf. Interval] } \\
\hline stringency_5lag & .1822433 & .0180317 & 10.11 & 0.000 & .1467716 & .2177149 \\
\hline cons & -7.713728 & 1.259423 & -6.12 & 0.000 & -10.19124 & -5.236218 \\
\hline
\end{tabular}

United States

\begin{tabular}{|c|c|c|c|c|c|c|}
\hline Source & SS & df & MS & Number of obs $=338$ & & \\
\hline & & & & $F(1,336)=83.49$ & & \\
\hline Model & 583.512663 & 1 & 583.512663 & Prob $>F=0.0000$ & & \\
\hline \multirow[t]{2}{*}{ Residual } & 2348.27748 & 336 & 6.98892109 & R-squared $=0.1990$ & & \\
\hline & & & & Adj R-squared=0.1966 & & \\
\hline Total & 2931.79015 & 337 & 8.69967403 & Root MSE = 2.6437 & & \\
\hline new_deaths_pe $\sim$ n & Coef. & Std. Err. & $\mathbf{t}$ & $\mathbf{P}>|\mathbf{t}|$ & {$[95 \%$ Con } & val] \\
\hline stringency_5lag & .097526 & .0106733 & 9.14 & 0.000 & .076531 & .1185209 \\
\hline _cons & -2.47667 & .7187014 & -3.45 & 0.001 & -3.890391 & -1.062949 \\
\hline
\end{tabular}

New deaths per million for the G7, Stringency Lag number of 10 days

Canada

\begin{tabular}{|c|c|c|c|c|c|c|}
\hline Source & SS & df & MS & \multicolumn{3}{|c|}{ Number of obs $=329$} \\
\hline & & & & \multicolumn{3}{|c|}{$F(1,327)=42.48$} \\
\hline Model & 95.0724331 & 1 & 95.0724331 & \multicolumn{3}{|c|}{ Prob $>$ F $=0.0000$} \\
\hline Residual & 731.77106 & 327 & 2.23783199 & \multicolumn{3}{|c|}{ R-squared $=0.1150$} \\
\hline & & & & \multicolumn{3}{|c|}{ Adj R-squared = 0.1123} \\
\hline Total & 826.843493 & 328 & 2.52086431 & \multicolumn{3}{|c|}{ Root MSE $=1.4959$} \\
\hline new_deaths_per $\sim$ n & Coef. & Std. Err. & $\mathbf{t}$ & $\mathbf{P}>|\mathbf{t}|$ & \multicolumn{2}{|c|}{ [95\% Conf. Interval] } \\
\hline stringency_10lag & .0385832 & .0059195 & 6.52 & 0.000 & .0269381 & .0502283 \\
\hline cons & -.8888085 & .3927274 & -2.26 & 0.024 & -1.6614 & -.1162175 \\
\hline
\end{tabular}

France

\begin{tabular}{|c|c|c|c|c|c|c|}
\hline Source & SS & df & MS & \multicolumn{3}{|c|}{ Number of obs $=352$} \\
\hline & & & & \multicolumn{3}{|c|}{$F(1,350)=111.93$} \\
\hline Model & 1725.69751 & 1 & 1725.69751 & \multicolumn{3}{|c|}{ Prob $>$ F $=0.0000$} \\
\hline Residual & 5396.3474 & 350 & 15.4181354 & \multicolumn{3}{|c|}{ R-squared $=0.2423$} \\
\hline & & & & \multicolumn{3}{|c|}{ Adj R-squared = 0.2401} \\
\hline Total & 7122.04491 & 351 & 20.2907262 & \multicolumn{3}{|c|}{ Root MSE = 3.9266} \\
\hline new_deaths_per $\sim$ n & Coef. & Std. Err. & $\mathbf{t}$ & $\mathbf{P}>|\mathbf{t}|$ & \multicolumn{2}{|c|}{ [95\% Conf. Interval] } \\
\hline stringency_10lag & .1086463 & .0102695 & 10.58 & 0.000 & .0884487 & .128844 \\
\hline cons & -3.256643 & .6556091 & -4.97 & 0.000 & -4.546072 & -1.967214 \\
\hline
\end{tabular}

Germany

\begin{tabular}{|c|c|c|c|c|c|c|}
\hline Source & SS & df & MS & \multicolumn{3}{|c|}{ Number of obs $=329$} \\
\hline & & & & \multicolumn{3}{|c|}{$F(1,327)=168.09$} \\
\hline Model & 1306.0365 & 1 & 1306.0365 & \multicolumn{3}{|c|}{ Prob $>$ F $=0.0000$} \\
\hline Residual & 2540.80527 & 327 & 7.77004671 & \multicolumn{3}{|c|}{ R-squared $=0.3395$} \\
\hline & & & & \multicolumn{3}{|c|}{ Adj R-squared $=0.3375$} \\
\hline Total & 3846.84177 & 328 & 11.7281761 & \multicolumn{3}{|c|}{ Root MSE $=\mathbf{2 . 7 8 7 5}$} \\
\hline new_deaths_per $\sim$ n & Coef. & Std. Err. & t & $\mathbf{P}>|\mathbf{t}|$ & \multicolumn{2}{|c|}{ [95\% Conf. Interval] } \\
\hline stringency_10lag & .1519831 & .0117227 & 12.96 & 0.000 & .1289216 & .1750446 \\
\hline cons & -7.383592 & .7454771 & -9.90 & 0.000 & -8.850128 & -5.917055 \\
\hline
\end{tabular}


Italy

\begin{tabular}{|c|c|c|c|c|c|c|}
\hline Source & SS & df & MS & \multicolumn{3}{|c|}{ Number of obs $=346$} \\
\hline & & & & \multicolumn{3}{|c|}{$F(1,344)=456.37$} \\
\hline Model & 3888.04338 & 1 & 3888.04338 & \multicolumn{3}{|c|}{ Prob $>$ F $=0.0000$} \\
\hline Residual & 2930.7148 & 344 & 8.51951977 & \multicolumn{3}{|c|}{ R-squared $=0.5702$} \\
\hline & & & & \multicolumn{3}{|c|}{ Adj R-squared $=0.5689$} \\
\hline Total & 6818.75819 & 345 & 19.7645165 & \multicolumn{3}{|c|}{ Root MSE $=2.9188$} \\
\hline new_deaths_per $\sim n$ & Coef. & Std. Err. & $\mathbf{t}$ & $\mathbf{P}>|\mathbf{t}|$ & \multicolumn{2}{|c|}{ [95\% Conf. Interval] } \\
\hline stringency_10lag & .1929895 & .0090339 & 21.36 & 0.000 & .1752208 & .2107581 \\
\hline cons & -8.516139 & .6169943 & -13.80 & 0.000 & -9.729695 & -7.302583 \\
\hline \multicolumn{7}{|l|}{ Japan } \\
\hline Source & SS & df & MS & \multicolumn{3}{|c|}{ Number of obs $=354$} \\
\hline & & & & \multicolumn{3}{|c|}{$F(1,352)=164.44$} \\
\hline Model & 5.02705714 & 1 & 5.02705714 & \multicolumn{3}{|c|}{ Prob $>F=0.0000$} \\
\hline Residual & 10.7608554 & 352 & .030570612 & \multicolumn{3}{|c|}{ R-squared = 0.3184} \\
\hline & & & & \multicolumn{3}{|c|}{ Adj R-squared $=0.3165$} \\
\hline Total & 15.7879125 & 353 & .044724965 & \multicolumn{3}{|c|}{ Root MSE $=.17484$} \\
\hline new_deaths_per $\sim$ n & Coef. & Std. Err. & $\mathbf{t}$ & $\mathbf{P}>|\mathbf{t}|$ & \multicolumn{2}{|c|}{ [95\% Conf. Interval] } \\
\hline stringency_10lag & .0142467 & .001111 & 12.82 & 0.000 & .0120617 & .0164318 \\
\hline cons -.3899326 & .0414841 & -9.40 & 0.000 & -.4715204 & -.3083448 & \\
\hline
\end{tabular}

United Kingdom

\begin{tabular}{|c|c|c|c|c|c|c|}
\hline Source & SS & df & MS & \multicolumn{3}{|c|}{ Number of obs $=332$} \\
\hline & & & & \multicolumn{3}{|c|}{$F(1,330)=75.97$} \\
\hline Model & 1955.21382 & 1 & 1955.21382 & \multicolumn{3}{|c|}{ Prob $>F=0.0000$} \\
\hline Residual & 8492.61004 & 330 & 25.7351819 & \multicolumn{3}{|c|}{ R-squared $=0.1871$} \\
\hline & & & & \multicolumn{3}{|c|}{ Adj R-squared = 0.1847 } \\
\hline Total & 10447.8239 & 331 & 31.5644225 & \multicolumn{3}{|c|}{ Root MSE $=5.073$} \\
\hline new_deaths_per n & Coef. & Std. Err. & $\mathbf{t}$ & $\mathbf{P}>|\mathbf{t}|$ & \multicolumn{2}{|c|}{ [95\% Conf. Interval] } \\
\hline stringency_10lag & .148517 & .0170389 & 8.72 & 0.000 & .1149983 & .1820356 \\
\hline cons & -5.245076 & 1.176611 & -4.46 & 0.000 & -7.559681 & -2.930471 \\
\hline
\end{tabular}

United States

\begin{tabular}{|c|c|c|c|c|c|c|}
\hline Source & SS & df & MS & \multicolumn{3}{|c|}{ Number of obs $=338$} \\
\hline & & & & \multicolumn{3}{|c|}{$F(1,336)=91.89$} \\
\hline Model & 629.626347 & 1 & 629.626347 & \multicolumn{3}{|c|}{ Prob $>$ F $=0.0000$} \\
\hline Residual & 2302.1638 & 336 & 6.85167798 & \multicolumn{3}{|c|}{ R-squared $=0.2148$} \\
\hline & & & & \multicolumn{3}{|c|}{ Adj R-squared = 0.2124} \\
\hline Total & 2931.79015 & 337 & 8.69967403 & \multicolumn{3}{|c|}{ Root MSE $=2.6176$} \\
\hline new_deaths_per $\sim$ n & Coef. & Std. Err. & $\mathbf{t}$ & $\mathbf{P}>|\mathbf{t}|$ & \multicolumn{2}{|c|}{ [95\% Conf. Interval] } \\
\hline stringency_10lag & .0892139 & .0093066 & 9.59 & 0.000 & .0709075 & .1075204 \\
\hline cons & -1.840922 & .6214142 & -2.96 & 0.003 & -3.063274 & -.6185692 \\
\hline
\end{tabular}

New deaths per million for the G7, Stringency Lag number of 15 days Canada

\begin{tabular}{|c|c|c|c|c|c|c|}
\hline Source & SS & df & MS & \multicolumn{3}{|c|}{ Number of obs $=329$} \\
\hline & & & & \multicolumn{3}{|c|}{$F(1,327)=39.75$} \\
\hline Model & 89.6132458 & 1 & 89.6132458 & \multicolumn{3}{|c|}{ Prob $>F=0.0000$} \\
\hline Residual & 737.230247 & 327 & 2.25452675 & \multicolumn{3}{|c|}{ R-squared $=0.1084$} \\
\hline & & & & \multicolumn{3}{|c|}{ Adj R-squared = 0.1057} \\
\hline Total & 826.843493 & 328 & 2.52086431 & \multicolumn{3}{|c|}{ Root MSE $=1.5015$} \\
\hline new_deaths_per $\sim$ n & Coef. & Std. Err. & $\mathbf{t}$ & $\mathbf{P}>|\mathbf{t}|$ & \multicolumn{2}{|c|}{ [95\% Conf. Interval] } \\
\hline stringency_15lag & .0330231 & .0052379 & 6.30 & 0.000 & .0227188 & .0433274 \\
\hline cons & -.4916726 & .3440802 & -1.43 & 0.154 & -1.168563 & .1852174 \\
\hline
\end{tabular}


France

\begin{tabular}{|c|c|c|c|c|c|c|}
\hline Source & SS & df & MS & \multicolumn{3}{|c|}{ Number of obs $=352$} \\
\hline & & & & \multicolumn{3}{|c|}{$F(1,350)=79.39$} \\
\hline Model & 1316.74159 & 1 & 1316.74159 & \multicolumn{3}{|c|}{ Prob $>$ F $=0.0000$} \\
\hline Residual & 5805.30333 & 350 & 16.5865809 & \multicolumn{3}{|c|}{ R-squared $=0.1849$} \\
\hline & & & & \multicolumn{3}{|c|}{ Adj R-squared = 0.1826} \\
\hline Total & 7122.04491 & 351 & 20.2907262 & \multicolumn{3}{|c|}{ Root MSE $=4.0727$} \\
\hline new_deaths_per $\sim$ n & Coef. & Std. Err. & $\mathbf{t}$ & $\mathbf{P}>|\mathbf{t}|$ & \multicolumn{2}{|c|}{ [95\% Conf. Interval] } \\
\hline stringency_15lag & .09125 & .0102414 & 8.91 & 0.000 & .0711075 & .1113926 \\
\hline cons & -2.13575 & .6492931 & -3.29 & 0.001 & -3.412757 & -.8587434 \\
\hline
\end{tabular}

Germany

\begin{tabular}{|c|c|c|c|c|c|c|}
\hline Source & SS & df & MS & \multicolumn{3}{|c|}{ Number of obs $=329$} \\
\hline & & & & \multicolumn{3}{|c|}{$F(1,327)=115.56$} \\
\hline Model & 1004.50784 & 1 & 1004.50784 & \multicolumn{3}{|c|}{ Prob $>$ F $=0.0000$} \\
\hline Residual & 2842.33393 & 327 & 8.69215269 & \multicolumn{3}{|c|}{ R-squared $=0.2611$} \\
\hline & & & & \multicolumn{3}{|c|}{ Adj R-squared = 0.2589} \\
\hline Total & 3846.84177 & 328 & 11.7281761 & \multicolumn{3}{|c|}{ Root MSE = 2.9482 } \\
\hline new_deaths_per $\sim$ n & Coef. & Std. Err. & $\mathbf{t}$ & $\mathbf{P}>|\mathbf{t}|$ & \multicolumn{2}{|c|}{ [95\% Conf. Interval] } \\
\hline stringency_15lag & .1234327 & .011482 & 10.75 & 0.000 & .1008448 & .1460205 \\
\hline _cons & -5.475697 & .7208341 & -7.60 & 0.000 & -6.893754 & -4.057639 \\
\hline
\end{tabular}

Italy

\begin{tabular}{|c|c|c|c|c|c|c|}
\hline Source & SS & df & MS & \multicolumn{3}{|c|}{ Number of obs $=346$} \\
\hline & & & & \multicolumn{3}{|c|}{$F(1,344)=319.38$} \\
\hline Model & 3282.84626 & 1 & 3282.84626 & \multicolumn{3}{|c|}{ Prob $>$ F $=0.0000$} \\
\hline Residual & 3535.91192 & 344 & 10.2788137 & \multicolumn{3}{|c|}{ R-squared $=0.4814$} \\
\hline & & & & \multicolumn{3}{|c|}{ Adj R-squared = 0.4799} \\
\hline Total & 6818.75819 & 345 & 19.7645165 & \multicolumn{3}{|c|}{ Root MSE $=3.2061$} \\
\hline new_deaths_per $\sim$ n & Coef. & Std. Err. & $\mathbf{t}$ & $\mathbf{P}>|\mathbf{t}|$ & \multicolumn{2}{|c|}{ [95\% Conf. Interval] } \\
\hline stringency_15lag & .1695471 & .0094872 & 17.87 & 0.000 & .150887 & .1882073 \\
\hline cons & -6.822534 & .6420873 & -10.63 & 0.000 & -8.085446 & -5.559623 \\
\hline \multicolumn{7}{|l|}{ Japan } \\
\hline Source & SS & df & MS & \multicolumn{3}{|c|}{ Number of obs $=354$} \\
\hline & & & & \multicolumn{3}{|c|}{$F(1,352)=132.80$} \\
\hline Model & 4.32471681 & 1 & 4.32471681 & \multicolumn{3}{|c|}{ Prob $>$ F $=0.0000$} \\
\hline Residual & 11.4631957 & 352 & .032565897 & \multicolumn{3}{|c|}{ R-squared $=0.2739$} \\
\hline & & & & \multicolumn{3}{|c|}{ Adj R-squared = 0.2719} \\
\hline Total & 15.7879125 & 353 & .044724965 & \multicolumn{3}{|c|}{ Root MSE =.18046 } \\
\hline new_deaths_per $\sim$ n & Coef. & Std. Err. & $\mathbf{t}$ & $\mathbf{P}>|\mathbf{t}|$ & \multicolumn{2}{|c|}{ [95\% Conf. Interval] } \\
\hline stringency_15lag & .0122697 & .0010647 & 11.52 & 0.000 & .0101757 & .0143638 \\
\hline cons & -.3102693 & .0392658 & -7.90 & 0.000 & -.3874944 & -.2330441 \\
\hline
\end{tabular}

United Kingdom

\begin{tabular}{|c|c|c|c|c|c|c|}
\hline Source & SS & df & MS & \multicolumn{3}{|c|}{ Number of obs $=332$} \\
\hline & & & & \multicolumn{3}{|c|}{$F(1,330)=42.01$} \\
\hline Model & 1179.885 & 1 & 1179.885 & \multicolumn{3}{|c|}{ Prob $>$ F $=0.0000$} \\
\hline Residual & 9267.93886 & 330 & 28.0846632 & \multicolumn{3}{|c|}{ R-squared $=0.1129$} \\
\hline & & & & \multicolumn{3}{|c|}{ Adj R-squared $=0.1102$} \\
\hline Total & 10447.8239 & 331 & 31.5644225 & \multicolumn{3}{|c|}{ Root MSE = 5.2995 } \\
\hline new_deaths_per $\sim$ n & Coef. & Std. Err. & $\mathbf{t}$ & $\mathbf{P}>|\mathbf{t}|$ & \multicolumn{2}{|c|}{ [95\% Conf. Interval] } \\
\hline stringency_15lag & .1075094 & .0165868 & 6.48 & 0.000 & .0748803 & .1401386 \\
\hline cons & -2.372317 & 1.132121 & -2.10 & 0.037 & -4.599401 & -.145233 \\
\hline
\end{tabular}


United States

\begin{tabular}{|c|c|c|c|c|c|c|}
\hline Source & SS & df & MS & \multicolumn{3}{|c|}{ Number of obs $=338$} \\
\hline & & & & \multicolumn{3}{|c|}{$F(1,336)=93.21$} \\
\hline Model & 636.696992 & 1 & 636.696992 & \multicolumn{3}{|c|}{ Prob $>$ F $=0.0000$} \\
\hline Residual & 2295.09316 & 336 & 6.83063439 & \multicolumn{3}{|c|}{ R-squared $=0.2172$} \\
\hline & & & & \multicolumn{3}{|c|}{ Adj R-squared = 0.2148} \\
\hline Total & 2931.79015 & 337 & 8.69967403 & \multicolumn{3}{|c|}{ Root MSE = 2.6135 } \\
\hline new_deaths_per $\sim$ n & Coef. & Std. Err. & t & $\mathbf{P}>|\mathbf{t}|$ & \multicolumn{2}{|c|}{ [95\% Conf. Interval] } \\
\hline stringency_15lag & .0813467 & .0084257 & 9.65 & 0.000 & .064773 & .0979204 \\
\hline cons & -1.249924 & .5577965 & -2.24 & 0.026 & -2.347137 & -.1527108 \\
\hline
\end{tabular}

New deaths per million for the G7, Stringency Lag number of 20 days

Canada

\begin{tabular}{|c|c|c|c|c|c|c|}
\hline Source & SS & df & MS & \multicolumn{3}{|c|}{ Number of obs = 329} \\
\hline & & & & \multicolumn{3}{|c|}{$F(1,327)=31.24$} \\
\hline Model & 72.1057043 & 1 & 72.1057043 & \multicolumn{3}{|c|}{ Prob $>$ F $=0.0000$} \\
\hline Residual & 754.737789 & 327 & 2.30806663 & \multicolumn{3}{|c|}{ R-squared = 0.0872} \\
\hline & & & & \multicolumn{3}{|c|}{ Adj R-squared = 0.0844} \\
\hline Total & 826.843493 & 328 & 2.52086431 & \multicolumn{3}{|c|}{ Root MSE = 1.5192} \\
\hline new_deaths_per $\sim$ n & Coef. & Std. Err. & $\mathbf{t}$ & $\mathbf{P}>|\mathbf{t}|$ & \multicolumn{2}{|c|}{ [95\% Conf. Interval] } \\
\hline stringency_20lag & .0268953 & .0048119 & 5.59 & 0.000 & .0174291 & .0363615 \\
\hline cons & -.0712539 & .3129128 & -0.23 & 0.820 & -.6868301 & .5443223 \\
\hline \multicolumn{7}{|l|}{ France } \\
\hline Source & SS & df & MS & \multicolumn{3}{|c|}{ Number of obs $=352$} \\
\hline & & & & \multicolumn{3}{|c|}{$F(1,350)=41.53$} \\
\hline Model & 755.394241 & 1 & 755.394241 & \multicolumn{3}{|c|}{ Prob $>$ F $=0.0000$} \\
\hline Residual & 6366.65067 & 350 & 18.1904305 & \multicolumn{3}{|c|}{ R-squared = 0.1061} \\
\hline & & & & \multicolumn{3}{|c|}{ Adj R-squared = 0.1035} \\
\hline Total & 7122.04491 & 351 & 20.2907262 & \multicolumn{3}{|c|}{ Root MSE $=4.265$} \\
\hline new_deaths_per $\sim$ n & Coef. & Std. Err. & $\mathbf{t}$ & $\mathbf{P}>|\mathbf{t}|$ & \multicolumn{2}{|c|}{ [95\% Conf. Interval] } \\
\hline stringency_20lag & .0667217 & .0103539 & 6.44 & 0.000 & .0463581 & .0870853 \\
\hline _cons & -.6201479 & .6518119 & -0.95 & 0.342 & -1.902109 & .6618129 \\
\hline
\end{tabular}

Germany

\begin{tabular}{|c|c|c|c|c|c|c|}
\hline Source & SS & df & MS & \multicolumn{3}{|c|}{ Number of obs $=329$} \\
\hline & & & & \multicolumn{3}{|c|}{$F(1,327)=82.40$} \\
\hline Model & 774.231996 & 1 & 774.231996 & \multicolumn{3}{|c|}{ Prob $>F=0.0000$} \\
\hline Residual & 3072.60978 & 327 & 9.39636017 & \multicolumn{3}{|c|}{ R-squared $=0.2013$} \\
\hline & & & & \multicolumn{3}{|c|}{ Adj R-squared = 0.1988} \\
\hline Total & 3846.84177 & 328 & 11.7281761 & \multicolumn{3}{|c|}{ Root MSE $=3.0653$} \\
\hline new_deaths_per $\sim$ n & Coef. & Std. Err. & $\mathbf{t}$ & $\mathbf{P}>|\mathbf{t}|$ & \multicolumn{2}{|c|}{ [95\% Conf. Interval] } \\
\hline stringency_20lag & .1011956 & .0111482 & 9.08 & 0.000 & .0792643 & .1231269 \\
\hline cons & -4.004547 & .690616 & -5.80 & 0.000 & -5.363158 & -2.645936 \\
\hline
\end{tabular}

Italy

\begin{tabular}{|c|c|c|c|c|c|c|}
\hline Source & SS & df & MS & \multicolumn{3}{|c|}{ Number of obs $=346$} \\
\hline & & & & \multicolumn{3}{|c|}{$F(1,344)=205.48$} \\
\hline Model & 2549.90063 & 1 & 2549.90063 & \multicolumn{3}{|c|}{ Prob $>F=0.0000$} \\
\hline Residual & 4268.85755 & 344 & 12.4094696 & \multicolumn{3}{|c|}{ R-squared $=0.3740$} \\
\hline & & & & \multicolumn{3}{|c|}{ Adj R-squared = 0.3721} \\
\hline Total & 6818.75819 & 345 & 19.7645165 & \multicolumn{3}{|c|}{ Root MSE = 3.5227 } \\
\hline new_deaths_per $\sim$ n & Coef. & Std. Err. & $\mathbf{t}$ & $\mathbf{P}>|\mathbf{t}|$ & \multicolumn{2}{|c|}{ [95\% Conf. Interval] } \\
\hline stringency_20lag & .1436887 & .0100239 & 14.33 & 0.000 & .1239728 & .1634046 \\
\hline _cons & -5.013629 & .6721617 & -7.46 & 0.000 & -6.335693 & -3.691565 \\
\hline
\end{tabular}


Japan

\begin{tabular}{|c|c|c|c|c|c|c|}
\hline Source & SS & df & MS & \multicolumn{3}{|c|}{ Number of obs $=354$} \\
\hline & & & & \multicolumn{3}{|c|}{$F(1,352)=108.95$} \\
\hline Model & 3.73150535 & 1 & 3.73150535 & \multicolumn{3}{|c|}{ Prob $>F=0.0000$} \\
\hline Residual & 12.0564071 & 352 & .034251157 & \multicolumn{3}{|c|}{ R-squared = 0.2364} \\
\hline & & & & \multicolumn{3}{|c|}{ Adj R-squared $=0.2342$} \\
\hline Total & 15.7879125 & 353 & .044724965 & \multicolumn{3}{|c|}{ Root MSE $=.18507$} \\
\hline new_deaths_per $\sim$ n & Coef. & Std. Err. & $\mathbf{t}$ & $\mathbf{P}>|\mathbf{t}|$ & \multicolumn{2}{|c|}{ [95\% Conf. Interval] } \\
\hline stringency_20lag & .0106237 & .0010178 & 10.44 & 0.000 & .0086219 & .0126255 \\
\hline cons & -.2443886 & .0370562 & -6.60 & 0.000 & -.317268 & -.1715092 \\
\hline
\end{tabular}

United Kingdom

\begin{tabular}{|c|c|c|c|c|c|c|}
\hline Source & SS & df & MS & \multicolumn{3}{|c|}{ Number of obs $=332$} \\
\hline & & & & \multicolumn{3}{|c|}{$F(1,330)=13.99$} \\
\hline Model & 424.977001 & 1 & 424.977001 & \multicolumn{3}{|c|}{ Prob $>$ F $=0.0002$} \\
\hline Residual & 10022.8469 & 330 & 30.3722632 & \multicolumn{3}{|c|}{ R-squared $=0.0407$} \\
\hline & & & & \multicolumn{3}{|c|}{ Adj R-squared = 0.0378} \\
\hline Total & 10447.8239 & 331 & 31.5644225 & \multicolumn{3}{|c|}{ Root MSE $=5.5111$} \\
\hline new_deaths_per $\sim$ n & Coef. & Std. Err. & $\mathbf{t}$ & $\mathbf{P}>|\mathbf{t}|$ & \multicolumn{2}{|c|}{ [95\% Conf. Interval] } \\
\hline stringency_20lag & .0608768 & .0162745 & 3.74 & 0.000 & .028862 & .0928917 \\
\hline cons & .7725027 & 1.097639 & 0.70 & 0.482 & -1.38675 & 2.931755 \\
\hline
\end{tabular}

United States

\begin{tabular}{|c|c|c|c|c|c|c|}
\hline Source & SS & df & MS & \multicolumn{3}{|c|}{ Number of obs $=338$} \\
\hline & & & & \multicolumn{3}{|c|}{$F(1,336)=76.68$} \\
\hline Model & 544.744737 & 1 & 544.744737 & \multicolumn{3}{|c|}{ Prob $>$ F $=0.0000$} \\
\hline Residual & 2387.04541 & 336 & 7.10430182 & \multicolumn{3}{|c|}{ R-squared $=0.1858$} \\
\hline & & & & \multicolumn{3}{|c|}{ Adj R-squared = 0.1834} \\
\hline Total & 2931.79015 & 337 & 8.69967403 & \multicolumn{3}{|c|}{ Root MSE = 2.6654 } \\
\hline new_deaths_per $\sim$ n | & Coef. & Std. Err. & t & $\mathbf{P}>|\mathbf{t}|$ & \multicolumn{2}{|c|}{ [95\% Conf. Interval] } \\
\hline stringency_20lag | & .0695305 & .0079403 & 8.76 & 0.000 & .0539114 & .0851496 \\
\hline cons $\mid$ & -.4254083 & .5211071 & -0.82 & 0.415 & -1.450452 & .5996351 \\
\hline
\end{tabular}

Excess Mortality During COVID-19: Deaths from All Causes Compared to Previous Years, All Ages

Shown in Figure 7 and Table 8 is how the number of weekly or monthly deaths in 2020-2021 differs as a percentage from the average number of deaths in the same period over the years 2015-2019. This metric is called the Pscore. The reported number of deaths might not count all deaths that occurred due to incomplete coverage and delays in death reporting.

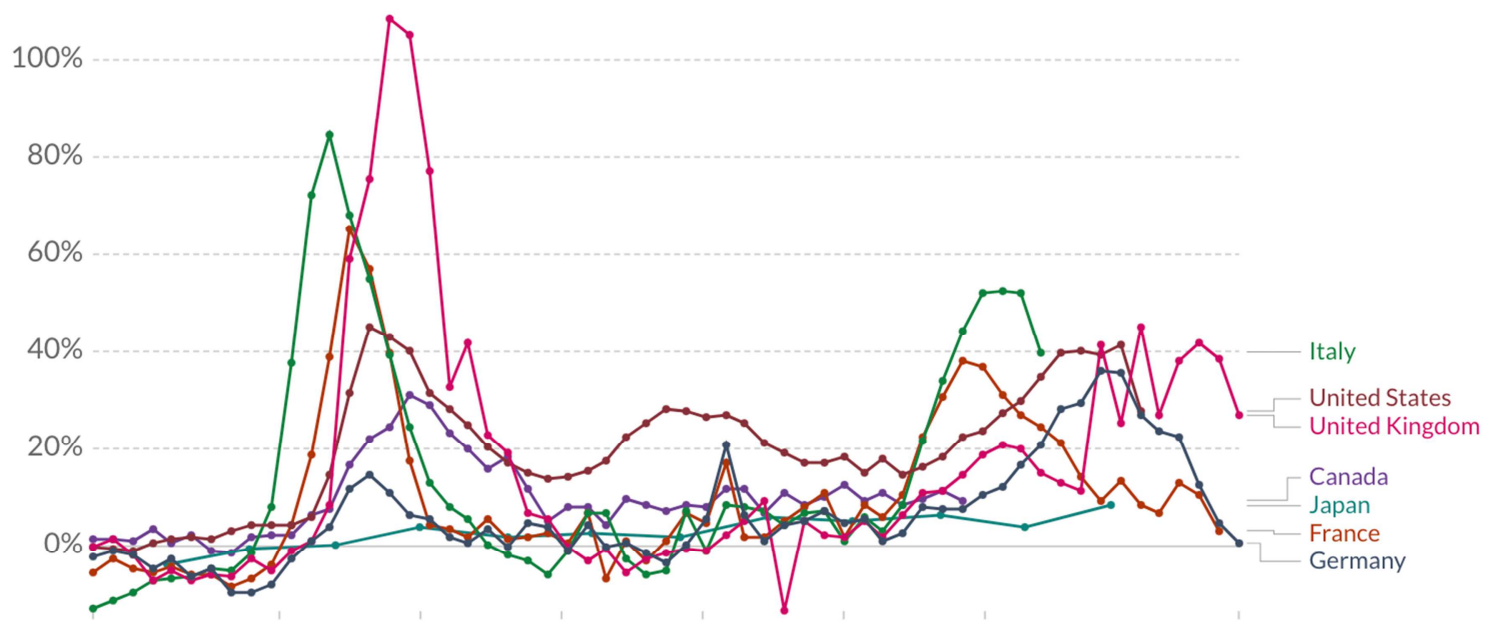

Jan 5,2020 Mar 11 Apr $30 \quad$ Jun $19 \quad$ Aug $8 \quad$ Sep $27 \quad$ Nov $16 \quad$ Feb 14, 2021

Figure 7. Excess Mortality G7.

Excess mortality is a term used in epidemiology and public health that refers to the number of deaths from all causes 
during a crisis above and beyond what we would have expected to see under "normal" conditions. In this case, we're interested in how deaths during the COVID-19 pandemic compare to the average number of deaths over the same period in previous years.

Excess mortality is a more comprehensive measure of the total impact of the pandemic on deaths than the COVID-19 confirmed death count alone. In addition to confirmed deaths, excess mortality captures COVID-19 deaths that have not been diagnosed and reported correctly, as well as deaths from other causes attributable to general crisis conditions. In future works, we intend to develop these points and the impact of vaccines.

Table 8. Excess mortality P-scores, all ages percent.

\begin{tabular}{|c|c|c|c|c|}
\hline Start & End & Absolute Change & Relative Change & \\
\hline Armenia & $-6 \%$ in Jan 31 & $79 \%$ in Dec 31 & $+85 \mathrm{pp}$ & $+1,437 \%$ \\
\hline Australia & $1 \%$ in Jan 5 & $-5 \%$ in Nov 22 & $-6 p p$ & $-456 \%$ \\
\hline Austria & $-11 \%$ in Jan 5 & $-5 \%$ in Feb 14 & $+6 \mathrm{pp}$ & $+57 \%$ \\
\hline Azerbaijan & $-5 \%$ in $\operatorname{Jan} 31$ & $196 \%$ in Dec 31 & $+201 \mathrm{pp}$ & $+4,213 \%$ \\
\hline Belarus & $-6 \%$ in $\operatorname{Jan} 31$ & $40 \%$ in Jun 30 & $+46 \mathrm{pp}$ & $+728 \%$ \\
\hline Belgium & $-6 \%$ in Jan 5 & $-11 \%$ in Feb 7 & $-5 \mathrm{pp}$ & $-75 \%$ \\
\hline Bulgaria & $-18 \%$ in Jan 5 & $-2 \%$ in Feb 14 & $+17 \mathrm{pp}$ & $+92 \%$ \\
\hline Canada & $2 \%$ in Jan 5 & $9 \%$ in Nov 8 & $+8 \mathrm{pp}$ & $+480 \%$ \\
\hline Chile & $8 \%$ in Jan 5 & $28 \%$ in Feb 14 & $+21 \mathrm{pp}$ & $+275 \%$ \\
\hline Costa Rica & $10 \%$ in Jan 31 & $-5 \%$ in Jun 30 & $-15 \mathrm{pp}$ & $-148 \%$ \\
\hline Croatia & $-16 \%$ in $\operatorname{Jan} 5$ & $21 \%$ in Jan 3 & $+38 \mathrm{pp}$ & $+232 \%$ \\
\hline Cyprus & $12 \%$ in Jan 5 & $-13 \%$ in $\operatorname{Jan} 10$ & $-25 \mathrm{pp}$ & $-208 \%$ \\
\hline Czechia & $-3 \%$ in Jan 5 & $54 \%$ in Jan 17 & $+57 \mathrm{pp}$ & $+2,225 \%$ \\
\hline Egypt & $-3 \%$ in Jan 31 & $13 \%$ in Aug 31 & $+15 \mathrm{pp}$ & $+574 \%$ \\
\hline England \& Wales & $<1 \%$ in Jan 5 & $29 \%$ in Feb 14 & $+28 \mathrm{pp}$ & $+6,445 \%$ \\
\hline Estonia & $-14 \%$ in Jan 5 & $1 \%$ in Jan 31 & $+15 \mathrm{pp}$ & $+109 \%$ \\
\hline Finland & $-10 \%$ in Jan 5 & $-12 \%$ in Feb 7 & $-2 \mathrm{pp}$ & $-21 \%$ \\
\hline France & $-5 \%$ in Jan 5 & $3 \%$ in Feb 7 & $+9 \mathrm{pp}$ & $+161 \%$ \\
\hline Georgia & $-9 \%$ in Jan 5 & $-5 \%$ in Jun 21 & $+3 \mathrm{pp}$ & $+39 \%$ \\
\hline Germany & $-2 \%$ in Jan 5 & $<1 \%$ in Feb 14 & $+3 \mathrm{pp}$ & $+127 \%$ \\
\hline Greece & $-3 \%$ in Jan 5 & $37 \%$ in Dec 6 & $+40 \mathrm{pp}$ & $+1,460 \%$ \\
\hline Hong Kong & $-3 \%$ in Jan 31 & $8 \%$ in Dec 31 & $+11 \mathrm{pp}$ & $+371 \%$ \\
\hline Hungary & $-10 \%$ in Jan 5 & $-7 \%$ in Jan 24 & $+2 \mathrm{pp}$ & $+23 \%$ \\
\hline Iceland & $24 \%$ in Jan 5 & $-29 \%$ in Jan 3 & $-53 p p$ & $-217 \%$ \\
\hline Israel & $8 \%$ in Jan 5 & $6 \%$ in Feb 7 & $-1 \mathrm{pp}$ & $-18 \%$ \\
\hline Italy & $-13 \%$ in $\operatorname{Jan} 5$ & $40 \%$ in Dec 6 & $+53 \mathrm{pp}$ & $+413 \%$ \\
\hline Japan & $-4 \%$ in Jan 31 & $8 \%$ in Dec 31 & $+12 \mathrm{pp}$ & $+313 \%$ \\
\hline Liechtenstein & $-62 \%$ in Jan 5 & $-29 \%$ in Feb 7 & $+33 \mathrm{pp}$ & $+54 \%$ \\
\hline Lithuania & $-6 \%$ in Jan 5 & $9 \%$ in Feb 14 & $+16 \mathrm{pp}$ & $+246 \%$ \\
\hline Luxembourg & $-27 \%$ in Jan 5 & $18 \%$ in $\operatorname{Jan} 3$ & $+45 \mathrm{pp}$ & $+164 \%$ \\
\hline Macao & $-4 \%$ in Jan 31 & $-4 \%$ in Dec 31 & $>-1 \mathrm{pp}$ & $-19 \%$ \\
\hline Malta & $-3 \%$ in Jan 5 & $-8 \%$ in Jan 3 & $-5 \mathrm{pp}$ & $-151 \%$ \\
\hline Mauritius & $7 \%$ in Jan 31 & $6 \%$ in Dec 31 & $>-1 \mathrm{pp}$ & $-8 \%$ \\
\hline Mexico & $-11 \%$ in Jan 5 & $68 \%$ in Jan 3 & $+79 \mathrm{pp}$ & $+696 \%$ \\
\hline Moldova & $-14 \%$ in Jan 31 & $17 \%$ in Nov 30 & $+31 \mathrm{pp}$ & $+218 \%$ \\
\hline Mongolia & $-3 \%$ in Jan 31 & $-3 \%$ in Nov 30 & $<1 \mathrm{pp}$ & $+24 \%$ \\
\hline Montenegro & $-43 \%$ in Jan 5 & $34 \%$ in Sep 27 & $+77 \mathrm{pp}$ & $+178 \%$ \\
\hline Netherlands & $-5 \%$ in Jan 5 & $8 \%$ in Feb 21 & $+14 \mathrm{pp}$ & $+251 \%$ \\
\hline New Zealand & $4 \%$ in $\operatorname{Jan} 5$ & $6 \%$ in Feb 7 & $+2 \mathrm{pp}$ & $+63 \%$ \\
\hline North Macedonia & $-14 \%$ in Jan 31 & $142 \%$ in Dec 31 & $+156 \mathrm{pp}$ & $+1,114 \%$ \\
\hline Northern Ireland & $-14 \%$ in Jan 5 & $11 \%$ in Feb 21 & $+25 \mathrm{pp}$ & $+179 \%$ \\
\hline Norway & $-7 \%$ in Jan 5 & $-7 \%$ in Jan 31 & $>-1 \mathrm{pp}$ & $>-1 \%$ \\
\hline Oman & $2 \%$ in $\operatorname{Jan} 31$ & $5 \%$ in Jan 31 & $+2 \mathrm{pp}$ & $+98 \%$ \\
\hline Philippines & $3 \%$ in $\operatorname{Jan} 31$ & $3 \%$ in Sep 30 & $<1 \mathrm{pp}$ & $+26 \%$ \\
\hline Poland & $>-1 \%$ in Jan 5 & $2 \%$ in Feb 14 & $+3 \mathrm{pp}$ & $+440 \%$ \\
\hline Portugal & $-10 \%$ in Jan 5 & $42 \%$ in Feb 7 & $+53 \mathrm{pp}$ & $+516 \%$ \\
\hline Qatar & $-3 \%$ in $\operatorname{Jan} 31$ & $5 \%$ in Dec 31 & $+8 \mathrm{pp}$ & $+289 \%$ \\
\hline Romania & $-11 \%$ in Jan 5 & $33 \%$ in Dec 27 & $+43 \mathrm{pp}$ & $+409 \%$ \\
\hline
\end{tabular}




\begin{tabular}{|c|c|c|c|c|}
\hline Start & End & Absolute Change & Relative Change & \\
\hline Russia & $-5 \%$ in Jan 31 & $58 \%$ in Dec 31 & $+63 \mathrm{pp}$ & $+1,299 \%$ \\
\hline San Marino & $-3 \%$ in Jan 31 & $110 \%$ in Dec 31 & $+114 \mathrm{pp}$ & $+3,382 \%$ \\
\hline Scotland & $-9 \%$ in Jan 5 & $12 \%$ in Feb 21 & $+21 \mathrm{pp}$ & $+238 \%$ \\
\hline Serbia & $-11 \%$ in $\operatorname{Jan} 31$ & $6 \%$ in Jan 31 & $+17 \mathrm{pp}$ & $+152 \%$ \\
\hline Singapore & $17 \%$ in Jan 31 & $8 \%$ in Sep 30 & $-9 \mathrm{pp}$ & $-54 \%$ \\
\hline Slovakia & $>-1 \%$ in $\operatorname{Jan} 5$ & $62 \%$ in Dec 27 & $+63 \mathrm{pp}$ & $+8,278 \%$ \\
\hline Slovenia & $-5 \%$ in Jan 5 & $32 \%$ in Jan 17 & $+37 \mathrm{pp}$ & $+720 \%$ \\
\hline South Korea & $6 \%$ in Jan 5 & $<1 \%$ in $\operatorname{Jan} 3$ & $-5 \mathrm{pp}$ & $-88 \%$ \\
\hline Spain & $-12 \%$ in Jan 5 & $2 \%$ in Feb 14 & $+14 \mathrm{pp}$ & $+116 \%$ \\
\hline Sweden & $-8 \%$ in Jan 5 & $-5 \%$ in Feb 7 & $+3 \mathrm{pp}$ & $+35 \%$ \\
\hline Switzerland & $-10 \%$ in Jan 5 & $-10 \%$ in Feb 7 & $<1 \mathrm{pp}$ & $+8 \%$ \\
\hline Taiwan & $4 \%$ in Jan 5 & $3 \%$ in Dec 27 & $-1 \mathrm{pp}$ & $-26 \%$ \\
\hline Thailand & $10 \%$ in Jan 31 & $12 \%$ in Dec 31 & $+2 \mathrm{pp}$ & $+16 \%$ \\
\hline Tunisia & $3 \%$ in $\operatorname{Jan} 31$ & $2 \%$ in Sep 30 & $>-1 \mathrm{pp}$ & $-34 \%$ \\
\hline Ukraine & $-6 \%$ in Jan 31 & $34 \%$ in Dec 31 & $+40 \mathrm{pp}$ & $+647 \%$ \\
\hline United Kingdom & $>-1 \%$ in $\operatorname{Jan} 5$ & $27 \%$ in Feb 14 & $+27 \mathrm{pp}$ & $+10,089 \%$ \\
\hline United States & $<1 \%$ in Jan 5 & $28 \%$ in Jan 10 & $+28 \mathrm{pp}$ & $+277,900 \%$ \\
\hline Uzbekistan & $9 \%$ in Jan 31 & $6 \%$ in Dec 31 & $-3 \mathrm{pp}$ & $-32 \%$ \\
\hline
\end{tabular}

Table 9. Power Distance Index and COVID-19 response to Stringency Index by Macro Area.

\begin{tabular}{|c|c|c|c|c|c|}
\hline Country & PDI & IDV & MAS & UAI & LTO \\
\hline Malaysia & 104 & 26 & 50 & 36 & \\
\hline Guatemala & 95 & 6 & 37 & 101 & \\
\hline Panama & 95 & 11 & 44 & 86 & \\
\hline Philippines & 94 & 32 & 64 & 44 & 19 \\
\hline Mexico & 81 & 30 & 69 & 82 & \\
\hline Venezuela & 81 & 12 & 73 & 76 & \\
\hline China & 80 & 20 & 66 & 40 & 118 \\
\hline Egypt & 80 & 38 & 52 & 68 & \\
\hline Iraq & 80 & 38 & 52 & 68 & \\
\hline Kuwait & 80 & 38 & 52 & 68 & \\
\hline Lebanon & 80 & 38 & 52 & 68 & \\
\hline Libya & 80 & 38 & 52 & 68 & \\
\hline Saudi Arabia & 80 & 38 & 52 & 68 & \\
\hline \multicolumn{6}{|l|}{ United Arab } \\
\hline Emirates & 80 & 38 & 52 & 68 & \\
\hline Ecuador & 78 & 8 & 63 & 67 & \\
\hline Indonesia & 78 & 14 & 46 & 48 & \\
\hline Ghana & 77 & 20 & 46 & 54 & 16 \\
\hline India & 77 & 48 & 56 & 40 & 61 \\
\hline Nigeria & 77 & 20 & 46 & 54 & 16 \\
\hline Sierra Leone & 77 & 20 & 46 & 54 & 16 \\
\hline Singapore & 74 & 20 & 48 & 8 & 48 \\
\hline Brazil & 69 & 38 & 49 & 76 & 65 \\
\hline France & 68 & 71 & 43 & 86 & \\
\hline Hong Kong & 68 & 25 & 57 & 29 & 96 \\
\hline Poland & 68 & 60 & 64 & 93 & \\
\hline Colombia & 67 & 13 & 64 & 80 & \\
\hline El Salvador & 66 & 19 & 40 & 94 & \\
\hline Turkey & 66 & 37 & 45 & 85 & \\
\hline Belgium & 65 & 75 & 54 & 94 & \\
\hline Ethiopia & 64 & 27 & 41 & 52 & 25 \\
\hline Kenya & 64 & 27 & 41 & 52 & 25 \\
\hline Peru & 64 & 16 & 42 & 87 & \\
\hline Tanzania & 64 & 27 & 41 & 52 & 25 \\
\hline Thailand & 64 & 20 & 34 & 64 & 56 \\
\hline Zambia & 64 & 27 & 41 & 52 & 25 \\
\hline Chile & 63 & 23 & 28 & 86 & \\
\hline Portugal & 63 & 27 & 31 & 104 & \\
\hline Uruguay & 61 & 36 & 38 & 100 & \\
\hline Greece & 60 & 35 & 57 & 112 & \\
\hline South Korea & 60 & 18 & 39 & 85 & 75 \\
\hline
\end{tabular}




\begin{tabular}{|c|c|c|c|c|c|}
\hline Country & PDI & IDV & MAS & UAI & LTO \\
\hline Iran & 58 & 41 & 43 & 59 & \\
\hline Taiwan & 58 & 17 & 45 & 69 & 87 \\
\hline Czech Republic & 57 & 58 & 57 & 74 & \\
\hline Spain & 57 & 51 & 42 & 86 & \\
\hline Pakistan & 55 & 14 & 50 & 70 & \\
\hline Japan & 54 & 46 & 95 & 92 & 80 \\
\hline Italy & 50 & 76 & 70 & 75 & \\
\hline Argentina & 49 & 46 & 56 & 86 & \\
\hline South Africa & 49 & 65 & 63 & 49 & \\
\hline Hungary & 46 & 55 & 88 & 82 & \\
\hline Jamaica & 45 & 39 & 68 & 13 & \\
\hline United States & 40 & 91 & 62 & 46 & 29 \\
\hline Netherlands & 38 & 80 & 14 & 53 & 44 \\
\hline Australia & 36 & 90 & 61 & 51 & 31 \\
\hline Costa Rica & 35 & 15 & 21 & 86 & \\
\hline Germany & 35 & 67 & 66 & 65 & 31 \\
\hline \multicolumn{6}{|l|}{ United } \\
\hline Kingdom & 35 & 89 & 66 & 35 & 25 \\
\hline Switzerland & 34 & 68 & 70 & 58 & \\
\hline Finland & 33 & 63 & 26 & 59 & \\
\hline Norway & 31 & 69 & 8 & 50 & 20 \\
\hline Sweden & 31 & 71 & 5 & 29 & 33 \\
\hline Ireland & 28 & 70 & 68 & 35 & \\
\hline New Zealand & 22 & 79 & 58 & 49 & 30 \\
\hline Denmark & 18 & 74 & 16 & 23 & \\
\hline Israel & 13 & 54 & 47 & 81 & \\
\hline Austria & 11 & 55 & 79 & 70 & \\
\hline
\end{tabular}

Table 10. Total deaths per million. Sensitivity: Different Stringency Lag Number of 20, 30 and 40 Days.

Lag number of 20

\begin{tabular}{|c|c|c|c|c|c|c|}
\hline Random-effects GLS regression & \multicolumn{6}{|c|}{ Number of obs $=49,538$} \\
\hline Group variable: country & \multicolumn{6}{|c|}{ Number of groups $=166$} \\
\hline R-sq: & \multicolumn{6}{|c|}{ Obs per group: } \\
\hline within $=0.0028$ & \multicolumn{6}{|c|}{$\min =25$} \\
\hline between $=0.0170$ & \multicolumn{6}{|l|}{ avg $=298.4$} \\
\hline overall $=0.0087$ & \multicolumn{6}{|l|}{$\max =357$} \\
\hline \multicolumn{7}{|l|}{ Wald chi2 $(1)=140.57$} \\
\hline $\operatorname{corr}\left(u_{i} \_, X\right)=0$ (assumed) & \multicolumn{6}{|c|}{ Prob $>$ chi $2=0.0000$} \\
\hline total_deaths_ $\sim$ n & Coef. & Std. Err. & $\mathbf{z}$ & $\mathbf{P}>|\mathbf{z}|$ & {$[95 \% \mathrm{Col}$} & \\
\hline stringency_20 g & .5593817 & .0471806 & 11.86 & 0.000 & .4669095 & .651854 \\
\hline _cons & 101.5556 & 15.31085 & 6.63 & 0.000 & 71.54692 & 131.5643 \\
\hline sigma_u & 193.51413 & & & & & \\
\hline sigma_e & 171.991 & & & & & \\
\hline rho & .55868249 & $\mathrm{n}$ of varianc & & & & \\
\hline
\end{tabular}

Lag number of 30

\begin{tabular}{|c|c|c|c|c|c|c|}
\hline Random-effects GLS regression & \multicolumn{6}{|c|}{ Number of obs $=48,525$} \\
\hline Group variable: country & \multicolumn{6}{|c|}{ Number of groups $=166$} \\
\hline R-sq: & \multicolumn{6}{|c|}{ Obs per group: } \\
\hline within $=0.0052$ & \multicolumn{6}{|l|}{$\min =25$} \\
\hline between $=0.0129$ & \multicolumn{6}{|c|}{ avg $=292.3$} \\
\hline overall $=\mathbf{0 . 0 0 8 8}$ & \multicolumn{6}{|l|}{$\max =352$} \\
\hline \multicolumn{7}{|l|}{ Wald chi2(1) 256.02} \\
\hline $\operatorname{corr}\left(\mathbf{u} \_\mathbf{i}, \mathbf{X}\right)=\mathbf{0}$ (assumed) & \multicolumn{6}{|c|}{ Prob $>$ chi $2=0.0000$} \\
\hline total_deaths_ $\sim$ n & Coef. & Std. Err. & $\mathbf{z}$ & $\mathbf{P}>|\mathbf{z}|$ & {$[95 \%$ Con } & \\
\hline stringency_30 g & .7286156 & .0455368 & 16.00 & 0.000 & .6393651 & .8178661 \\
\hline _cons & 94.18775 & 15.5779 & 6.05 & 0.000 & 63.65562 & 124.7199 \\
\hline sigma_u & 197.2944 & & & & & \\
\hline sigma_e & 170.6772 & & & & & \\
\hline rho & .57195843 & on of varian & i) & & & \\
\hline
\end{tabular}


Lag number of 40

\begin{tabular}{|c|c|c|c|c|c|c|}
\hline Random-effects GLS regression & \multicolumn{6}{|c|}{ Number of obs $=47,283$} \\
\hline Group variable: country & \multicolumn{6}{|c|}{ Number of groups $=166$} \\
\hline R-sq: & \multicolumn{6}{|c|}{ Obs per group: } \\
\hline within $=0.0054$ & \multicolumn{6}{|c|}{$\min =25$} \\
\hline between $=0.0096$ & \multicolumn{6}{|l|}{$\operatorname{avg}=284.8$} \\
\hline overall $=0.0073$ & \multicolumn{6}{|l|}{$\max =343$} \\
\hline \multicolumn{7}{|l|}{ Wald chi2 $(1)=255.26$} \\
\hline $\operatorname{corr}\left(u_{-} \mathbf{i}, \mathbf{X}\right)=0$ (assumed) & \multicolumn{6}{|c|}{ Prob $>$ chi $2=0.0000$} \\
\hline total_deaths_p n & Coef. & Std. Err. & $\mathbf{z}$ & $\mathbf{P}>|\mathbf{z}|$ & {$[95 \% \mathrm{Co}$} & \\
\hline stringency 40lag & .7146716 & .0447313 & 15.98 & 0.000 & .627 & .8023433 \\
\hline cons & 98.4569 & 15.91409 & 6.19 & 0.000 & 67.26585 & 129.648 \\
\hline sigma u & 201.81732 & & & & & \\
\hline sigma e & 169.33417 & & & & & \\
\hline rho & .58685466 & of variance & & & & \\
\hline
\end{tabular}

Table 11. Total deaths per million. By selected countries.

-> country $=$ United States

\begin{tabular}{|c|c|c|c|c|c|c|}
\hline Source & SS & df & MS & \multicolumn{3}{|c|}{ Number of obs $=339$} \\
\hline & & & & \multicolumn{3}{|c|}{$F(1,337)=160.87$} \\
\hline Model & 12747585.5 & 1 & $\mathbf{1 2 7 4 7 5 8 5 . 5}$ & \multicolumn{3}{|c|}{ Prob $>$ F $=0.0000$} \\
\hline Residual & 26704365.4 & 337 & 79241.4403 & \multicolumn{3}{|c|}{ R-squared $=0.3231$} \\
\hline & & & & \multicolumn{3}{|c|}{ Adj R-squared = 0.3211 } \\
\hline Total & 39451950.8 & 338 & 116721.748 & \multicolumn{3}{|c|}{ Root MSE $=281.5$} \\
\hline total_deaths_p $\sim$ n & Coef. & Std. Err. & $\mathbf{t}$ & $\mathbf{P}>|\mathbf{t}|$ & \multicolumn{2}{|c|}{ [95\% Conf. Interval] } \\
\hline stringency_30lag & 9.353206 & .7374333 & 12.68 & 0.000 & 7.902654 & 10.80376 \\
\hline cons & -41.47281 & 47.55285 & -0.87 & 0.384 & -135.0106 & 52.06499 \\
\hline \multicolumn{7}{|l|}{$->$ country $=$ Canada } \\
\hline Source & SS & df & MS & \multicolumn{3}{|c|}{ Number of obs $=330$} \\
\hline & & & & \multicolumn{3}{|c|}{$F(1,328)=195.38$} \\
\hline Model & 1920894.58 & 1 & 1920894.58 & \multicolumn{3}{|c|}{ Prob $>F=0.0000$} \\
\hline Residual & 3224717.42 & 328 & 9831.45555 & \multicolumn{3}{|c|}{ R-squared $=0.3733$} \\
\hline & & & & \multicolumn{3}{|c|}{ Adj R-squared $=\mathbf{0 . 3 7 1 4}$} \\
\hline Total & 5145612 & 329 & 15640.1581 & \multicolumn{3}{|c|}{ Root MSE $=99.154$} \\
\hline total_deaths_p $\sim$ n & Coef. & Std. Err. & $\mathbf{t}$ & $\mathbf{P}>|\mathbf{t}|$ & \multicolumn{2}{|c|}{ [95\% Conf. Interval] } \\
\hline stringency_30lag & 3.791176 & .2712258 & 13.98 & 0.000 & 3.257614 & 4.324737 \\
\hline cons & 10.4784 & 17.32947 & 0.60 & 0.546 & -23.61253 & 44.56933 \\
\hline
\end{tabular}

Table 12. New deaths per million All Countries.

\begin{tabular}{|c|c|c|c|c|c|c|}
\hline Random-effects GLS regression & \multicolumn{6}{|c|}{ Number of obs $=50651$} \\
\hline Group variable: country & \multicolumn{6}{|c|}{ Number of groups = 182} \\
\hline R-sq: within $=0.0129$ & \multicolumn{6}{|c|}{ Obs per group: $\min =24$} \\
\hline between $=\mathbf{0 . 3 8 6 8}$ & \multicolumn{6}{|c|}{ avg $=278.3$} \\
\hline \multirow[t]{2}{*}{ overall $=0.0631$} & \multicolumn{6}{|l|}{$\max =346$} \\
\hline & \multicolumn{6}{|c|}{ Wald chi2 $(15)=780.92$} \\
\hline $\operatorname{corr}\left(\mathbf{u} \_\mathbf{i}, \mathbf{X}\right)=0$ (assumed) & \multicolumn{6}{|c|}{ Prob $>$ chi $2=0.0000$} \\
\hline new_deaths_per_million & Coef. & Std. Err. & $\mathbf{z}$ & $\mathbf{P}>|\mathbf{z}|$ & \multicolumn{2}{|c|}{ [95\% Conf. Interval] } \\
\hline reproduction_rate & -.3449307 & .0297394 & -11.60 & 0.000 & -.4032189 & -.2866424 \\
\hline stringency_5lag & .0177845 & .0007274 & 24.45 & 0.000 & .0163589 & .0192101 \\
\hline population density & -.0001706 & .0000892 & -1.91 & 0.056 & -.0003455 & $4.24 \mathrm{e}-06$ \\
\hline median age & .0100886 & .0188078 & 0.54 & 0.592 & -.0267741 & .0469513 \\
\hline aged_65_older & -.0386095 & .0610652 & -0.63 & 0.527 & -.1582951 & .081076 \\
\hline aged_70_older & .1277235 & .0726755 & 1.76 & 0.079 & -.0147178 & .2701648 \\
\hline log_gdp_per_ca & .4431614 & .1137241 & 3.90 & 0.000 & .2202662 & .6660565 \\
\hline cardiovasc_death_rate & -.000236 & .0007485 & -0.32 & 0.753 & -.001703 & .001231 \\
\hline diabetes_prevalence & .0060938 & .0193497 & 0.31 & 0.753 & -.0318309 & .0440185 \\
\hline female_smokers & .0502692 & .0119729 & 4.20 & 0.000 & .0268027 & .0737357 \\
\hline male_smokers & -.0118881 & .004623 & -2.57 & 0.010 & -.020949 & -.0028272 \\
\hline handwashing_facilities & .0034953 & .0021489 & 1.63 & 0.104 & -.0007165 & .0077071 \\
\hline hospital_beds_per_thousand & .0085024 & .0404034 & 0.21 & 0.833 & -.0706868 & .0876916 \\
\hline life expectancy & .0311515 & .0123913 & 2.51 & 0.012 & .006865 & .055438 \\
\hline human_development_index & -4.590632 & .9956138 & -4.61 & 0.000 & -6.541999 & -2.639265 \\
\hline cons & -3.745812 & 1.046093 & -3.58 & 0.000 & -5.796116 & -1.695507 \\
\hline
\end{tabular}




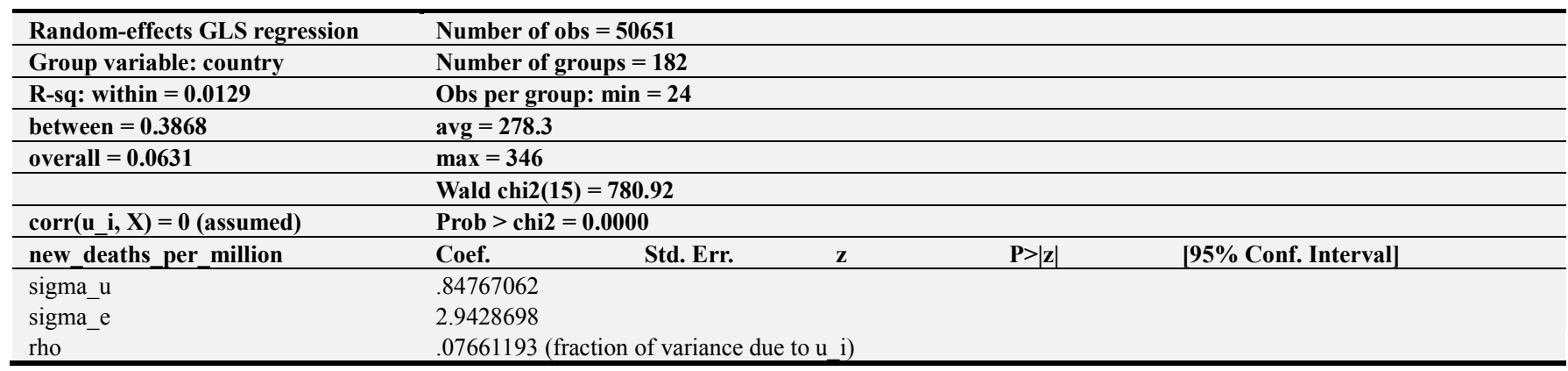

Table 13. Total deaths per million All countries.

\begin{tabular}{|c|c|c|c|c|c|c|}
\hline Random-effects GLS regression & \multicolumn{6}{|c|}{ Number of obs $=50651$} \\
\hline Group variable: country & \multicolumn{6}{|c|}{ Number of groups $=182$} \\
\hline R-sq: within $=0.0197$ & \multicolumn{6}{|c|}{ Obs per group: $\min =24$} \\
\hline between $=0.4518$ & \multicolumn{6}{|l|}{$\operatorname{avg}=278.3$} \\
\hline \multirow[t]{2}{*}{ overall $=0.2823$} & \multicolumn{6}{|l|}{$\max =346$} \\
\hline & \multicolumn{6}{|c|}{ Wald chi2 $(15)=1161.93$} \\
\hline $\operatorname{corr}\left(\mathbf{u} \_\mathbf{i}, \mathbf{X}\right)=\mathbf{0}$ (assumed) & \multicolumn{6}{|c|}{ Prob $>$ chi $2=0.0000$} \\
\hline total_deaths_per_million & Coef. & Std. Err. & $\mathbf{z}$ & $\mathbf{P}>|\mathbf{z}|$ & \multicolumn{2}{|c|}{ [95\% Conf. Interval] } \\
\hline reproduction_rate & -38.48277 & 1.232555 & -31.22 & 0.000 & -40.89853 & -36.06701 \\
\hline stringency_5lag & .3693264 & .030636 & 12.06 & 0.000 & .3092809 & .429372 \\
\hline population_density & -.0252863 & .0111139 & -2.28 & 0.023 & -.0470692 & -.0035034 \\
\hline median_age & -.5218229 & 2.348235 & -0.22 & 0.824 & -5.124278 & 4.080632 \\
\hline aged_65_older & -3.254617 & 7.74269 & -0.42 & 0.674 & -18.43001 & 11.92078 \\
\hline aged_70_older & 12.33805 & 9.215409 & 1.34 & 0.181 & -5.723816 & 30.39992 \\
\hline log_gdp_per_ca & 93.45486 & 14.40793 & 6.49 & 0.000 & 65.21583 & 121.6939 \\
\hline cardiovasc_death_rate & -.0543218 & .0945109 & -0.57 & 0.565 & -.2395597 & .1309161 \\
\hline female_smokers & 4.130391 & 1.516664 & 2.72 & 0.006 & 1.157784 & 7.102999 \\
\hline male_smokers & -1.191603 & .5851307 & -2.04 & 0.042 & -2.338438 & -.044768 \\
\hline handwashing_facilities & .3463704 & .2718617 & 1.27 & 0.203 & -.1864688 & .8792096 \\
\hline hospital_beds_per_thousand & -6.208756 & 5.105651 & -1.22 & 0.224 & -16.21565 & 3.798136 \\
\hline life_expectancy & 8.881065 & 1.5698 & 5.66 & 0.000 & 5.804314 & 11.95782 \\
\hline human_development_index & -881.6999 & 125.8153 & -7.01 & 0.000 & -1128.293 & -635.1065 \\
\hline _cons & -752.706 & 132.5091 & -5.68 & 0.000 & -1012.419 & -492.993 \\
\hline sigma_u & 109.55672 & & & & & \\
\hline sigma_e & 121.34479 & & & & & \\
\hline rho & .44908036 & of variance & u i) & & & \\
\hline
\end{tabular}

Table 14. Regressions for G7 changing lags.

G7: 5 days lag of Stringency index.

\begin{tabular}{|c|c|c|c|c|c|c|}
\hline Random-effects GLS regression & \multicolumn{6}{|c|}{ Number of obs $=2,282$} \\
\hline Group variable: country & \multicolumn{6}{|c|}{ Number of groups $=7$} \\
\hline R-sq: & \multicolumn{6}{|c|}{ Obs per group: } \\
\hline within $=0.3130$ & \multicolumn{6}{|c|}{$\min =\mathbf{3 1 7}$} \\
\hline between $=1.0000$ & \multicolumn{6}{|c|}{$\operatorname{avg}=326.0$} \\
\hline overall $=0.4159$ & \multicolumn{6}{|l|}{$\max =336$} \\
\hline & \multicolumn{6}{|c|}{ Wald $\operatorname{chi} 2(8)=1618.41$} \\
\hline $\operatorname{corr}\left(\mathbf{u} \_\mathbf{i}, \mathbf{X}\right)=\mathbf{0}$ (assumed) & \multicolumn{6}{|c|}{ Prob $>$ chi $2=0.0000$} \\
\hline reproduction_rate & .9820385 & .1682688 & 5.84 & 0.000 & .6522378 & 1.311839 \\
\hline stringency 5lag & .1684631 & .0057608 & 29.24 & 0.000 & .1571722 & .179754 \\
\hline population & $9.10 \mathrm{e}-09$ & $1.84 \mathrm{e}-09$ & 4.95 & 0.000 & $5.50 \mathrm{e}-09$ & $1.27 \mathrm{e}-08$ \\
\hline median_age & -.459043 & .0719255 & -6.38 & 0.000 & -.6000144 & -.3180715 \\
\hline aged_65_older & .463677 & .3617146 & 1.28 & 0.200 & -.2452705 & 1.172624 \\
\hline aged_70_older & .0626447 & .410799 & 0.15 & 0.879 & -.7425066 & .867796 \\
\hline log_gdp_per_ca & -9.01679 & 1.156705 & -7.80 & 0.000 & -11.28389 & -6.749689 \\
\hline cardiovasc_death_rate & .0161058 & .0113453 & 1.42 & 0.156 & -.0061307 & .0383422 \\
\hline sigma_u & \multicolumn{6}{|l|}{0} \\
\hline sigma_e & \multicolumn{6}{|l|}{2.9544667} \\
\hline rho & \multicolumn{6}{|c|}{0 (fraction of variance due to $\mathrm{u} i$ ) } \\
\hline Random-effects GLS regression & \multicolumn{6}{|c|}{ Number of obs $=2,282$} \\
\hline
\end{tabular}




\begin{tabular}{|c|c|c|c|c|c|c|}
\hline Group variable: country & \multicolumn{6}{|c|}{ Number of groups $=7$} \\
\hline R-sq: & \multicolumn{6}{|c|}{ Obs per group: } \\
\hline within $=0.1991$ & \multicolumn{6}{|c|}{$\min =317$} \\
\hline between $=1.0000$ & \multicolumn{6}{|c|}{ avg $=326.0$} \\
\hline overall $=0.5814$ & \multicolumn{6}{|l|}{$\max =336$} \\
\hline & \multicolumn{6}{|c|}{ Wald chi $2(8)=3157.41$} \\
\hline $\operatorname{corr}\left(\mathrm{u} \_\mathrm{i}, \mathrm{X}\right)=0$ (assumed) & \multicolumn{6}{|c|}{ Prob $>$ chi $2=0.0000$} \\
\hline total_deaths_per_mi $\sim \mathrm{n}$ & Coef. & Std. Err. & $\mathrm{z}$ & $\mathrm{P}>|\mathrm{z}|$ & \multicolumn{2}{|c|}{ [95\% Conf. Interval] } \\
\hline reproduction_rate & -238.4194 & 12.03247 & -19.81 & 0.000 & -262.0026 & -214.8362 \\
\hline stringency 5lag & -.2714073 & .4119373 & -0.66 & 0.510 & -1.07879 & .535975 \\
\hline population & $2.63 \mathrm{e}-06$ & $1.31 \mathrm{e}-07$ & 19.97 & 0.000 & $2.37 \mathrm{e}-06$ & $2.88 \mathrm{e}-06$ \\
\hline median_age & -5.607394 & 5.143212 & -1.09 & 0.276 & -15.6879 & 4.473116 \\
\hline aged_65_older & -165.6524 & 25.86528 & -6.40 & 0.000 & -216.3474 & -114.9573 \\
\hline aged_70_older & 113.1174 & 29.37519 & 3.85 & 0.000 & 55.54307 & 170.6917 \\
\hline log_gdp_per_ca & -3268.702 & 82.71305 & -39.52 & 0.000 & -3430.817 & -3106.588 \\
\hline cardiovasc_death_rate & 1.171426 & .811275 & 1.44 & 0.149 & -.4186439 & 2.761496 \\
\hline cons & 37080.47 & 880.239 & 42.13 & 0.000 & 35355.23 & 38805.71 \\
\hline sigma_u & \multicolumn{6}{|c|}{0} \\
\hline sigma_e & \multicolumn{6}{|l|}{211.26637} \\
\hline rho & \multicolumn{6}{|c|}{$0($ fraction of variance due to $u \mathrm{i})$} \\
\hline
\end{tabular}

G7: 10 days lag of Stringency index

\begin{tabular}{|c|c|c|c|c|c|c|}
\hline Random-effects GLS regression & \multicolumn{6}{|c|}{ Number of obs $=2,282$} \\
\hline Group variable: country & \multicolumn{6}{|c|}{ Number of groups $=7$} \\
\hline R-sq: & \multicolumn{6}{|c|}{ Obs per group: } \\
\hline within $=0.2854$ & \multicolumn{6}{|c|}{$\min =317$} \\
\hline between $=1.0000$ & \multicolumn{6}{|l|}{ avg $=326.0$} \\
\hline overall $=0.3924$ & \multicolumn{6}{|l|}{$\max =336$} \\
\hline & \multicolumn{6}{|c|}{ Wald chi2 $(8)=1468.01$} \\
\hline $\operatorname{corr}\left(\mathrm{u} \_\mathrm{i}, \mathrm{X}\right)=0$ (assumed) & \multicolumn{6}{|c|}{ Prob $>$ chi $2=0.0000$} \\
\hline new_deaths_per_mill $\sim \mathrm{n}$ & Coef. & Std. Err. & $\mathrm{z}$ & $\mathrm{P}>|\mathrm{z}|$ & \multicolumn{2}{|c|}{ [95\% Conf. Interval] } \\
\hline reproduction_rate & 1.981977 & .199233 & 9.95 & 0.000 & 1.591487 & 2.372466 \\
\hline stringency_10lag & .1682839 & .0062104 & 27.10 & 0.000 & .1561118 & .180456 \\
\hline population & $8.24 \mathrm{e}-09$ & $1.88 \mathrm{e}-09$ & 4.38 & 0.000 & $4.55 \mathrm{e}-09$ & $1.19 \mathrm{e}-08$ \\
\hline median_age & -.4605611 & .0734848 & -6.27 & 0.000 & -.6045887 & -.3165336 \\
\hline aged_65_older & .5737018 & .3703565 & 1.55 & 0.121 & -.1521837 & 1.299587 \\
\hline aged_70_older & -.0687287 & .4197393 & -0.16 & 0.870 & -.8914027 & .7539453 \\
\hline log_gdp_per_ca & -9.04728 & 1.187221 & -7.62 & 0.000 & -11.37419 & -6.72037 \\
\hline cardiovasc_death_rate & .0203444 & .0115755 & 1.76 & 0.079 & -.0023431 & .0430319 \\
\hline _cons -- & 92.65438 & 12.69021 & 7.30 & 0.000 & 67.78203 & 117.5267 \\
\hline sigma_u & \multicolumn{6}{|l|}{0} \\
\hline sigma_e & \multicolumn{6}{|l|}{3.0132724} \\
\hline rho & \multicolumn{6}{|c|}{0 (fraction of variance due to $u \_i$ ) } \\
\hline Random-effects GLS regression & \multicolumn{6}{|c|}{ Number of obs $=2,282$} \\
\hline Group variable: country & \multicolumn{6}{|c|}{ Number of groups $=7$} \\
\hline R-sq: & \multicolumn{6}{|c|}{ Obs per group: } \\
\hline within $=0.1991$ & \multicolumn{6}{|c|}{$\min =317$} \\
\hline between $=1.0000$ & \multicolumn{6}{|l|}{$\operatorname{avg}=326.0$} \\
\hline overall $=0.5814$ & \multicolumn{6}{|l|}{$\max =336$} \\
\hline & \multicolumn{6}{|c|}{ Wald chi2 $(8)=3157.47$} \\
\hline $\operatorname{corr}\left(\mathrm{u} \_\mathrm{i}, \mathrm{X}\right)=0$ (assumed) & \multicolumn{6}{|c|}{ Prob $>$ chi $2=0.0000$} \\
\hline total_deaths_per_mi $\sim \mathrm{n}$ & Coef. & Std. Err. & $\mathrm{z}$ & $\mathrm{P}>|\mathrm{z}|$ & \multicolumn{2}{|c|}{ [95\% Conf. Interval] } \\
\hline reproduction_rate & -227.1187 & 13.96852 & -16.26 & 0.000 & -254.4965 & -199.7409 \\
\hline stringency_10lag & .2959683 & .4354185 & 0.68 & 0.497 & -.5574362 & 1.149373 \\
\hline population & $2.60 \mathrm{e}-06$ & $1.32 \mathrm{e}-07$ & 19.68 & 0.000 & $2.34 \mathrm{e}-06$ & $2.86 \mathrm{e}-06$ \\
\hline median_age & -6.772395 & 5.15213 & -1.31 & 0.189 & -16.87038 & 3.325594 \\
\hline aged_65_older & -159.2354 & 25.96626 & -6.13 & 0.000 & -210.1284 & -108.3425 \\
\hline aged_70_older & 108.9476 & 29.42856 & 3.70 & 0.000 & 51.26873 & 166.6266 \\
\hline log_gdp_per_ca & -3230.585 & 83.23784 & -38.81 & 0.000 & -3393.728 & -3067.442 \\
\hline cardiovase_death_rate & 1.199408 & .8115735 & 1.48 & 0.139 & -.3912468 & 2.790063 \\
\hline _cons & 36604.88 & 889.7294 & 41.14 & 0.000 & 34861.04 & 38348.72 \\
\hline$\overline{\text { sigma_u }}$ & 0 & & & & & \\
\hline sigma_e & 211.26507 & & & & & \\
\hline rho & 0 (fraction $\mathrm{c}$ & due to $\mathrm{u}$ i) & & & & \\
\hline
\end{tabular}


G7: 15 days lag of Stringency index

\begin{tabular}{|c|c|c|c|c|c|c|}
\hline Random-effects GLS regression & \multicolumn{6}{|c|}{ Number of obs $=2,282$} \\
\hline Group variable: country & \multicolumn{6}{|c|}{ Number of groups $=7$} \\
\hline R-sq: & \multicolumn{6}{|c|}{ Obs per group: } \\
\hline within $=0.2166$ & \multicolumn{6}{|l|}{$\min =317$} \\
\hline between $=1.0000$ & \multicolumn{6}{|l|}{ avg $=326.0$} \\
\hline overall $=0.3339$ & \multicolumn{6}{|l|}{$\max =336$} \\
\hline & \multicolumn{6}{|c|}{ Wald chi2 $(8)=1139.35$} \\
\hline $\operatorname{corr}\left(\mathrm{u} \_\mathrm{i}, \mathrm{X}\right)=0$ (assumed) & \multicolumn{6}{|c|}{ Prob $>$ chi $2=0.0000$} \\
\hline new deaths per mill n & Coef. & Std. Err. & $\mathrm{z}$ & $\mathrm{P}>|\mathrm{z}|$ & \multicolumn{2}{|c|}{ [95\% Conf. Interval] } \\
\hline reproduction_rate & 2.143525 & .235622 & 9.10 & 0.000 & 1.681714 & 2.605335 \\
\hline stringency_15lag & .1471112 & .0067853 & 21.68 & 0.000 & .1338123 & .1604101 \\
\hline population & $8.73 \mathrm{e}-09$ & $1.98 \mathrm{e}-09$ & 4.41 & 0.000 & $4.85 \mathrm{e}-09$ & $1.26 \mathrm{e}-08$ \\
\hline median_age & -.4191535 & .077064 & -5.44 & 0.000 & -.570196 & -.2681109 \\
\hline aged_65_older & .3905103 & .389037 & 1.00 & 0.315 & -.3719882 & 1.153009 \\
\hline aged_70_older & .0212089 & .4401611 & 0.05 & 0.962 & -.841491 & .8839087 \\
\hline log_gdp_per_ca & -10.46006 & 1.250014 & -8.37 & 0.000 & -12.91004 & -8.010077 \\
\hline cardiovasc_death_rate & .0219914 & .0121261 & 1.81 & 0.070 & -.0017754 & .0457581 \\
\hline _cons & 109.3482 & 13.41002 & 8.15 & 0.000 & 83.06506 & 135.6314 \\
\hline sigma_u & \multicolumn{6}{|l|}{0} \\
\hline sigma_e & \multicolumn{6}{|l|}{3.1550475} \\
\hline rho & \multicolumn{6}{|c|}{0 (fraction of variance due to $u_{-} \_$) } \\
\hline Random-effects GLS regression & \multicolumn{6}{|c|}{ Number of obs $=2,282$} \\
\hline Group variable: country & \multicolumn{6}{|c|}{ Number of groups $=7$} \\
\hline R-sq: & \multicolumn{6}{|c|}{ Obs per group: } \\
\hline within $=0.2033$ & $\min =317$ & & & & & \\
\hline between $=1.0000$ & avg $=326$. & & & & & \\
\hline overall $=0.5836$ & $\max =336$ & & & & & \\
\hline & Wald chi2( & & & & & \\
\hline corr $\left(\mathrm{u} \_\mathrm{i}, \mathrm{X}\right)=0$ (assumed) & Prob $>$ chi 2 & & & & & \\
\hline total_deaths_per_mi $\sim \mathrm{n}$ & Coef. & Std. Err. & $\mathrm{z}$ & $\mathrm{P}>|\mathrm{z}|$ & {$[95 \%$ Conf } & \\
\hline reproduction_rate & -190.7303 & 15.73659 & -12.12 & 0.000 & -221.5734 & -159.8871 \\
\hline stringency_15lag & 1.588861 & .4531705 & 3.51 & 0.000 & .7006628 & 2.477059 \\
\hline population & $2.52 \mathrm{e}-06$ & $1.32 \mathrm{e}-07$ & 19.08 & 0.000 & $2.26 \mathrm{e}-06$ & $2.78 \mathrm{e}-06$ \\
\hline median_age & -9.457585 & 5.146903 & -1.84 & 0.066 & -19.54533 & .6301609 \\
\hline aged_65_older & -143.5209 & 25.98278 & -5.52 & 0.000 & -194.4462 & -92.59563 \\
\hline aged_70_older & 98.16315 & 29.39723 & 3.34 & 0.001 & 40.54565 & 155.7807 \\
\hline log_gdp_per_ca & -3143.701 & 83.48521 & -37.66 & 0.000 & -3307.329 & -2980.073 \\
\hline cardiovasc_death_rate & 1.310599 & .8098718 & 1.62 & 0.106 & -.276721 & 2.897918 \\
\hline cons & 35502.91 & 895.6206 & 39.64 & 0.000 & 33747.53 & 37258.29 \\
\hline sigma_u & 0 & & & & & \\
\hline sigma_e & 210.71751 & & & & & \\
\hline rho & 0 (fraction & due to $u \_$i) & & & & \\
\hline 7: 20 days lag of Stringency inde & & & & & & \\
\hline Random-effects GLS regression & Number of & & & & & \\
\hline Group variable: country & Number of & & & & & \\
\hline R-sq: & Obs per gro & & & & & \\
\hline within $=0.1174$ & $\min =317$ & & & & & \\
\hline between $=1.0000$ & $\operatorname{avg}=326.0$ & & & & & \\
\hline overall $=0.2495$ & $\max =336$ & & & & & \\
\hline & Wald chi2( & & & & & \\
\hline $\operatorname{corr}\left(u_{-} \mathrm{i}, \mathrm{X}\right)=0$ (assumed) & Prob $>$ chi 2 & & & & & \\
\hline new_deaths_per_mill n & Coef. & Std. Err. & $\mathrm{z}$ & $\mathrm{P}>|\mathrm{z}|$ & {$[95 \%$ Cont } & \\
\hline reproduction_rate | & .8433022 & .2630022 & 3.21 & 0.001 & .3278274 & 1.358777 \\
\hline stringency_20lag | & .0900844 & .0070836 & 12.72 & 0.000 & .0762008 & .1039681 \\
\hline population & $1.17 \mathrm{e}-08$ & $2.10 \mathrm{e}-09$ & 5.57 & 0.000 & $7.60 \mathrm{e}-09$ & $1.58 \mathrm{e}-08$ \\
\hline median_age & -.3009672 & .0817546 & -3.68 & 0.000 & -.4612032 & -.1407312 \\
\hline aged_65_older & -.2753852 & .4129944 & -0.67 & 0.505 & -1.084839 & .5340689 \\
\hline aged_70_older & .4636635 & .4673455 & 0.99 & 0.321 & -.4523168 & 1.379644 \\
\hline log_gdp_per_ca & -14.31097 & 1.323376 & -10.81 & 0.000 & -16.90473 & -11.7172 \\
\hline cardiovasc_death_rate & .0186673 & .0128757 & 1.45 & 0.147 & -.0065685 & .0439032 \\
\hline cons & 157.6571 & 14.19727 & 11.10 & 0.000 & 129.831 & 185.4832 \\
\hline
\end{tabular}




\begin{tabular}{|c|c|c|c|c|c|c|}
\hline sigma_u & \multicolumn{6}{|l|}{0} \\
\hline sigma_e & \multicolumn{6}{|l|}{3.3488722} \\
\hline rho & \multicolumn{6}{|c|}{0 (fraction of variance due to $\mathrm{u} \_\mathrm{i}$ ) } \\
\hline Random-effects GLS regression & \multicolumn{6}{|c|}{ Number of obs $=2,282$} \\
\hline Group variable: country & \multicolumn{6}{|c|}{ Number of groups $=7$} \\
\hline R-sq: & \multicolumn{6}{|c|}{ Obs per group: } \\
\hline within $=0.2179$ & \multicolumn{6}{|c|}{$\min =317$} \\
\hline between $=1.0000$ & \multicolumn{6}{|l|}{ avg $=326.0$} \\
\hline overall $=0.5912$ & \multicolumn{6}{|l|}{$\max =336$} \\
\hline & \multicolumn{6}{|c|}{ Wald chi2 $(8)=3287.58$} \\
\hline corr(u_i, X) = 0 (assumed) & \multicolumn{6}{|c|}{ Prob $>$ chi $2=0.0000$} \\
\hline total_deaths_per_mi n & Coef. & Std. Err. & $\mathrm{z}$ & $\mathrm{P}>|\mathrm{z}|$ & {$[95 \%$ Conf } & \\
\hline reproduction_rate & -136.0167 & 16.39635 & -8.30 & 0.000 & -168.153 & -103.8805 \\
\hline stringency_20lag & 3.273042 & .4416141 & 7.41 & 0.000 & 2.407495 & 4.13859 \\
\hline population & $2.42 \mathrm{e}-06$ & $1.31 \mathrm{e}-07$ & 18.45 & 0.000 & $2.16 \mathrm{e}-06$ & $2.68 \mathrm{e}-06$ \\
\hline median_age & -12.95185 & 5.096828 & -2.54 & 0.011 & -22.94145 & -2.962249 \\
\hline aged_65_older & -122.4291 & 25.74732 & -4.76 & 0.000 & -172.893 & -71.96531 \\
\hline aged_70_older & 83.338 & 29.13573 & 2.86 & 0.004 & 26.23301 & 140.443 \\
\hline log_gdp_per_ca & -3031.249 & 82.50327 & -36.74 & 0.000 & -3192.952 & -2869.545 \\
\hline cardiovasc_death_rate & 1.495636 & .8027093 & 1.86 & 0.062 & -.0776448 & 3.068918 \\
\hline _cons & 34063.37 & 885.1005 & 38.49 & 0.000 & 32328.6 & 35798.13 \\
\hline sigma_u & 0 & & & & & \\
\hline sigma_e & 208.77885 & & & & & \\
\hline rho & 0 (fraction $\mathrm{C}$ & due to $\mathrm{u}$ i) & & & & \\
\hline
\end{tabular}

Tab 15. Macroarea Stringency Coef and Std.Err.

-> macroarea $=$ Africa

\begin{tabular}{|c|c|c|c|c|c|c|}
\hline Source & SS & df & MS & \multicolumn{3}{|c|}{ Number of obs $=13,804$} \\
\hline & & & & \multicolumn{3}{|c|}{$F(2,13801)=620.71$} \\
\hline Model & 4462397.3 & 2 & 2231198.65 & \multicolumn{3}{|c|}{ Prob $>F=0.0000$} \\
\hline Residual & 49609315.4 & 13,801 & 3594.61745 & \multicolumn{3}{|c|}{ R-squared $=0.0825$} \\
\hline & & & & \multicolumn{3}{|c|}{ Adj R-squared $=0.0824$} \\
\hline Total & 54071712.7 & 13,803 & 3917.38845 & \multicolumn{3}{|c|}{ Root MSE = 59.955 } \\
\hline total_deaths_ $\sim$ n & Coef. & Std. Err. & $\mathbf{t}$ & $\mathbf{P}>|\mathbf{t}|$ & \multicolumn{2}{|c|}{ [95\% Conf. Interval] } \\
\hline stringency_20 g & .0087896 & .0239606 & 0.37 & 0.714 & -.0381766 & .0557557 \\
\hline gdp_per_capita & .0034733 & .0000999 & 34.76 & 0.000 & .0032774 & .0036692 \\
\hline cons & 7.319556 & 1.485048 & 4.93 & 0.000 & 4.40866 & 10.23045 \\
\hline
\end{tabular}

-> macroarea $=$ Asia

\begin{tabular}{|c|c|c|c|c|c|c|}
\hline Source & SS & df & MS & \multicolumn{3}{|c|}{ Number of obs $=11,500$} \\
\hline & & & & \multicolumn{3}{|c|}{$F(2,11497)=28.73$} \\
\hline Model & 635839.029 & 2 & 317919.514 & \multicolumn{3}{|c|}{ Prob $>$ F $=0.0000$} \\
\hline Residual & 127215936 & 11,497 & 11065.1419 & \multicolumn{3}{|c|}{ R-squared $=\mathbf{0 . 0 0 5 0}$} \\
\hline & & & & \multicolumn{3}{|c|}{ Adj R-squared = 0.0048} \\
\hline Total & 127851775 & 11,499 & 11118.5125 & \multicolumn{3}{|c|}{ Root MSE = 105.19 } \\
\hline total_deaths_ $\sim$ n & Coef. & Std. Err. & $\mathbf{t}$ & $\mathbf{P}>|\mathbf{t}|$ & \multicolumn{2}{|c|}{ [95\% Conf. Interval] } \\
\hline stringency_20 g & .371414 & .0496451 & 7.48 & 0.000 & .2741012 & .4687268 \\
\hline gdp_per_capita & .0000692 & .0000371 & 1.86 & 0.062 & $-3.58 \mathrm{e}-06$ & .000142 \\
\hline cons & 37.146 & 3.514532 & 10.57 & 0.000 & 30.25691 & 44.03508 \\
\hline
\end{tabular}

$->$ macroarea $=$ Europe

\begin{tabular}{|c|c|c|c|c|c|c|}
\hline Source & SS & df & MS & \multicolumn{3}{|c|}{ Number of obs $=12,598$} \\
\hline & & & & \multicolumn{3}{|c|}{$F(2,12595)=476.53$} \\
\hline Model & 116633365 & 2 & 58316682.5 & \multicolumn{3}{|c|}{ Prob $>F=0.0000$} \\
\hline Residual & $1.5414 \mathrm{e}+09$ & 12,595 & 122378.092 & \multicolumn{3}{|c|}{ R-squared $=0.0703$} \\
\hline & & & & \multicolumn{3}{|c|}{ Adj R-squared = 0.0702} \\
\hline Total & $1.6580 \mathrm{e}+09$ & 12,597 & 131617.483 & \multicolumn{3}{|c|}{ Root MSE $=349.83$} \\
\hline total_deaths_ $\sim n$ & Coef. & Std. Err. & t & $\mathbf{P}>|\mathbf{t}|$ & \multicolumn{2}{|c|}{ [95\% Conf. Interval] } \\
\hline stringency_20 g & 3.753256 & .1583847 & 23.70 & 0.000 & 3.442798 & 4.063714 \\
\hline gdp_per_capita & .0037118 & .0001747 & 21.24 & 0.000 & .0033693 & .0040543 \\
\hline cons & -47.19201 & 11.4543 & -4.12 & 0.000 & -69.64419 & -24.73983 \\
\hline
\end{tabular}


-> macroarea $=$ North America

\begin{tabular}{|c|c|c|c|c|c|c|}
\hline Source & SS & df & MS & \multicolumn{3}{|c|}{ Number of obs $=4,974$} \\
\hline & & & & \multicolumn{3}{|c|}{$F(2,4971)=496.41$} \\
\hline Model & 50461663.3 & 2 & 25230831.6 & \multicolumn{3}{|c|}{ Prob $>F=0.0000$} \\
\hline Residual & 252658991 & 4,971 & 50826.5924 & \multicolumn{3}{|c|}{ R-squared $=0.1665$} \\
\hline & & & & \multicolumn{3}{|c|}{ Adj R-squared $=0.1661$} \\
\hline Total & 303120654 & 4,973 & 60953.2785 & \multicolumn{3}{|c|}{ Root $M S E=225.45$} \\
\hline total_deaths_ $\sim$ n & Coef. & Std. Err. & $\mathbf{t}$ & $\mathbf{P}>|\mathbf{t}|$ & \multicolumn{2}{|c|}{ [95\% Conf. Interval] } \\
\hline stringency_20 g & .9438481 & .1417317 & 6.66 & 0.000 & .6659914 & 1.221705 \\
\hline cons & .1988554 & 10.63833 & 0.02 & 0.985 & -20.65697 & 21.05468 \\
\hline
\end{tabular}

-> macroarea $=$ Oceania

\begin{tabular}{|c|c|c|c|c|c|c|}
\hline Source & SS & df & MS & \multicolumn{3}{|c|}{ Number of obs $=1,022$} \\
\hline & & & & \multicolumn{3}{|c|}{$F(2,1019)=273.31$} \\
\hline Model & 48641.4214 & 2 & 24320.7107 & \multicolumn{3}{|c|}{ Prob $>F=0.0000$} \\
\hline Residual & 90676.9976 & 1,019 & 88.9862587 & \multicolumn{3}{|c|}{ R-squared $=0.3491$} \\
\hline & & & & \multicolumn{3}{|c|}{ Adj R-squared =0.3479 } \\
\hline Total & 139318.419 & 1,021 & 136.452908 & \multicolumn{3}{|c|}{ Root MSE $=9.4333$} \\
\hline total_deaths_ $\sim n$ & Coef. & Std. Err. & $\mathbf{t}$ & $\mathbf{P}>|\mathbf{t}|$ & \multicolumn{2}{|c|}{ [95\% Conf. Interval] } \\
\hline stringency_20 g & .1619389 & .015238 & 10.63 & 0.000 & .1320374 & .1918404 \\
\hline cons & -9.223279 & .8833533 & -10.44 & 0.000 & -10.95668 & -7.48988 \\
\hline
\end{tabular}

-> macroarea $=$ South America

\begin{tabular}{|c|c|c|c|c|c|c|}
\hline Source & SS & df & MS & \multicolumn{3}{|c|}{ Number of obs $=3,757$} \\
\hline & & & & \multicolumn{3}{|c|}{$F(2,3754)=2.34$} \\
\hline Model & 559895.862 & 2 & 279947.931 & \multicolumn{3}{|c|}{ Prob $>F=0.0961$} \\
\hline Residual & 448347667 & 3,754 & 119431.984 & \multicolumn{3}{|c|}{ R-squared $=0.0012$} \\
\hline & & & & \multicolumn{3}{|c|}{ Adj R-squared $=0.0007$} \\
\hline Total & 448907563 & 3,756 & 119517.455 & \multicolumn{3}{|c|}{ Root $\mathrm{MSE}=345.59$} \\
\hline total_deaths_ $\sim n$ & Coef. & Std. Err. & $\mathbf{t}$ & $\mathbf{P}>|\mathbf{t}|$ & \multicolumn{2}{|c|}{ [95\% Conf. Interval] } \\
\hline stringency_20 g & -.6106061 & .3228851 & -1.89 & 0.059 & -1.243653 & .0224413 \\
\hline cons & 370.0127 & 30.8378 & 12.00 & 0.000 & 309.5522 & 430.4731 \\
\hline
\end{tabular}

\section{References}

[1] Board, G. P. M. (2019). A world at risk: annual report on global preparedness for health emergencies. Geneva, Switzerland: World Health Organization.

[2] Board, G. P. M. (2020). A world in disorder. Geneva, Switzerland: World Health Organization.

[3] Buckley, C., Kirkpatrick, D., \& Hernández, J. (2021). The 25 days that changed the world, Globe and Mail.

[4] Cugat, G. And Narita, F. (2020) How COVID-19 Will Increase Inequality in Emerging Markets and Developing Economies, International Monetary Fund Blog.

[5] Falk, G., Carter, J. A., Nicchitta, I. A., Nyhof, E. C, Romero, P. D. (Jan, 2021) Unemployment Rates During the COVID-19 Pandemic: In Brief, Congressional Research Service.

[6] Finch WH and Hernández Finch ME (2020) Poverty and Covid-19: Rates of Incidence and Deaths in the United States During the First 10 Weeks of the Pandemic. Front. Sociol. 5: 47. doi: $10.3389 /$ fsoc. 2020.00047 .

[7] GINI index (World Bank estimate) Data: data.worldbank.org. Retrieved 2021-3-9.

[8] Haug, N., Geyrhofer, L., Londei, A., Dervic, E., Desvars-
Larrive, A., Loreto, V.,... \& Klimek, P. (2020). Ranking the effectiveness of worldwide COVID-19 government interventions. Nature human behaviour, 1-10.

[9] Helbing, D. (2013). Globally networked risks and how to respond. Nature, 497 (7447), 51.

[10] Hofstede, G. (2009). Power Distance Index.

[11] Jackson, J. K., Weiss, M. A, Schwarzenberg, A. B., Nelson, R. M., Sutter, K. M., Sutherland, M. D. (Feb 2021) Global Economic Effects of COVID-19, Congressional Research Service.

[12] John Hopkins University \& Medicine, (2021), Cases and Mortality by Country, https://coronavirus.jhu.edu/data/mortality last accessed March 9, 2021

[13] Leduc, S., \& Liu, Z. (2020). The Uncertainty Channel of the Coronavirus. Economic Letters.

[14] OECD, Key Indicators of the Labour Market (KILM): 20012002, International Labour Organisation, Geneva, 2002, page 704.

[15] O'Toole, A. \& Hill, V (2021). Rambaut Group, University of Edinborgh.

[16] Richter, F (Jan 2021). IMPACT OF COVID-19 PANDEMIC ON MENTAL HEALTH. 
[17] Pandemic Causes Spike in Anxiety \& Depression.

[18] Szymanski, B. K., Lin, X., Asztalos, A., \& Sreenivasan, S. (2015). Failure dynamics of the global risk network. Scientific reports, 5, 10998.

[19] Tullo, Lois (October 2017). Global Risks and Trends Framework (GRAFT). Global Risk Institute (GRI).

[20] Tullo, Lois (March 2020). GRAFT: Covid-19 Implications. Global Risk Institute (GRI).

[21] Turchin, A. V. (2010). Structure of the global catastrophe. The risks of dying out humanity in the XX century./AV Turchin-M.

[22] WEF (2020). The Global Risk Report 2020, Insight Report 15th Edition In partnership with Marsh \& McLennan and Zurich Insurance Group.

[23] World Health Organization (Jan 2021), New COVID-19 variants fuelling Africa's second wave.

[24] Goldin, I and Muggah, R., WEF (October 2020) COVID-19 is increasing multiple kinds of inequality. Here's what we can do about it? https://www.weforum.org/agenda/2020/10/covid-19- is-increasing-multiple-kinds-of-inequality-here-s-what-wecan-do-about-it/

[25] World Bank (2018), GINI index (World Bank Estimate) https://data.worldbank.org/indicator/SI.POV.GINI?view=map last accessed March 9, 2021.

[26] World Bank. (2020). Poverty and Shared Prosperity 2020: Reversals of Fortune. The World Bank.

[27] Mukherjee Siddhartha (February 22, 2021) Why Does the Pandemic Seem to Be Hitting Some Countries Harder Than Others? The New Yorker. Coronavirus Chronicles, March 1, 2021 Issue.

[28] Schellekens, P., and Sourrouille, D. M. (2020). COVID-19 mortality in rich and poor countries: a tale of two pandemics? World Bank Policy Research Working Paper, (9260).

[29] Lai, S., Ruktanonchai, W., Zhou, L., Prosper, O., Luo, W., Floyd, J., Wesolowski, A., Zhang, C., Du, X., Tatem, A., Effect of non-pharmaceutical interventions for containing the COVID-19 outbreak: an observational and modelling study. medRxiv2020.03.03.20029843; https://doi.org/10.1101/2020.03.03.20029843. 